\title{
2005s-06 \\ Asymptotic distribution of a simple linear estimator for VARMA models in echelon form
}

\author{
Jean-Marie Dufour, Tarek Jouini
}

Série Scientifique
Scientific Series

Montréal

Février 2005

(C) 2005 Jean-Marie Dufour, Tarek Jouini. Tous droits réservés. All rights reserved. Reproduction partielle permise avec citation du document source, incluant la notice $\mathbb{C}$.

Short sections may be quoted without explicit permission, iffull credit, including (C) notice, is given to the source.
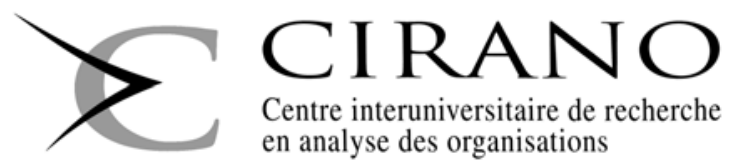

Centre interuniversitaire de recherche en analyse des organisations 


\section{CIRANO}

Le CIRANO est un organisme sans but lucratif constitué en vertu de la Loi des compagnies du Québec. Le financement de son infrastructure et de ses activités de recherche provient des cotisations de ses organisations-membres, d'une subvention d'infrastructure du Ministère du Développement économique et régional et de la Recherche, de même que des subventions et mandats obtenus par ses équipes de recherche.

CIRANO is a private non-profit organization incorporated under the Québec Companies Act. Its infrastructure and research activities are funded through fees paid by member organizations, an infrastructure grant from the Ministère du Développement économique et régional et de la Recherche, and grants and research mandates obtained by its research teams.

PARTENAIRE MAJEUR

$$
\text { Les organisations-partenaires / The Partner Organizations }
$$

. Ministère du Développement économique et régional et de la Recherche [MDERR]

PARTENAIRES

. Alcan inc.

. Axa Canada

. Banque du Canada

. Banque Laurentienne du Canada

. Banque Nationale du Canada

. Banque Royale du Canada

. Bell Canada

. BMO Groupe Financier

. Bombardier

. Bourse de Montréal

. Caisse de dépôt et placement du Québec

. Développement des ressources humaines Canada [DRHC]

. Fédération des caisses Desjardins du Québec

. GazMétro

. Groupe financier Norshield

. Hydro-Québec

. Industrie Canada

. Ministère des Finances du Québec

. Pratt \& Whitney Canada Inc.

. Raymond Chabot Grant Thornton

. Ville de Montréal

. École Polytechnique de Montréal

. HEC Montréal

. Université Concordia

. Université de Montréal

. Université du Québec

. Université du Québec à Montréal

. Université Laval

. Université McGill

. Université de Sherbrooke

ASSOCIE A :

. Institut de Finance Mathématique de Montréal (IFM²)

. Laboratoires universitaires Bell Canada

. Réseau de calcul et de modélisation mathématique $\left[\mathrm{RCM}^{2}\right]$

. Réseau de centres d'excellence MITACS (Les mathématiques des technologies de l'information et des systèmes complexes)

Les cahiers de la série scientifique $(\mathrm{CS})$ visent à rendre accessibles des résultats de recherche effectuée au CIRANO afin de susciter échanges et commentaires. Ces cahiers sont écrits dans le style des publications scientifiques. Les idées et les opinions émises sont sous l'unique responsabilité des auteurs et ne représentent pas nécessairement les positions du CIRANO ou de ses partenaires.

This paper presents research carried out at CIRANO and aims at encouraging discussion and comment. The observations and viewpoints expressed are the sole responsibility of the authors. They do not necessarily represent positions of CIRANO or its partners. 


\title{
Asymptotic distribution of a simple linear estimator for VARMA models in echelon form"
}

\author{
Jean-Marie Dufour ${ }^{\prime}$, Tarek Jouini $i^{*}$
}

\begin{abstract}
Résumé / Abstract
Dans cet article, nous étudions la distribution asymptotique d'un estimateur linéaire simple en deux étapes (de type Hannan-Rissanen) pour un processus vectoriel autorégressif-moyennemobile (VARMA) stationnaire et inversible, formulé sous la forme échelon. Nous donnons des conditions générales qui assurent la convergence et la normalité asymptotique de l'estimateur. Nous fournissons aussi un estimateur convergent de la matrice de covariance asymptotique de l'estimateur, ce qui permet de construire facilement des tests et des intervalles de confiance.
\end{abstract}

Mots-clés : séries chronologiques; VARMA, stationnaire, inversible, forme échelon, estimation, normalité asymptotique, bootstrap, Hannan-Rissanen.

In this paper, we study the asymptotic distribution of a simple two-stage (Hannan-Rissanentype) linear estimator for stationary invertible vector autoregressive moving average (VARMA) models in the echelon form representation. General conditions for consistency and asymptotic normality are given. A consistent estimator of the asymptotic covariance matrix of the estimator is also provided, so that tests and confidence intervals can easily be constructed.

Keywords: time series, VARMA, stationary; invertible; echelon form, estimation, asymptotic normality, bootstrap, Hannan-Rissanen.

Codes JEL : C3, C32, C53.

\footnotetext{
${ }^{*}$ The authors thank Denis Pelletier, an anonymous referee, and the Editor Pierre Duchesne for several useful comments. This work was supported by the Canada Research Chair Program (Chair in Econometrics, Université de Montréal), the Alexander-von-Humboldt Foundation (Germany), the Institut de finance mathématique de Montréal (IFM2), the Canadian Network of Centres of Excellence [program on Mathematics of Information Technology and Complex Systems (MITACS)], the Canada Council for the Arts (Killam Fellowship), the Natural Sciences and Engineering Research Council of Canada, the Social Sciences and Humanities Research Council of Canada, the Fonds de recherche sur la société et la culture (Québec), and the Fonds de recherche sur la nature et les technologies (Québec).

${ }^{\dagger}$ Canada Research Chair Holder (Econometrics). Centre interuniversitaire de recherche en analyse des organisations (CIRANO), Centre interuniversitaire de recherche en économie quantitative (CIREQ), and Département de sciences économiques, Université de Montréal. Mailing address: Département de sciences économiques, Université de Montréal, C.P. 6128 succursale Centre-ville, Montréal, Québec, Canada H3C 3J7. TEL: 1 (514) 343 2400; FAX: 1 (514) 343 5831; e-mail: jean.marie.dufour@umontreal.ca. Web page: http://www.fas.umontreal.ca/SCECO/Dufour

$\$$ CIRANO, CIREQ, and Département de sciences économiques, Université de Montréal. Mailing address: Département de sciences économiques, Université de Montréal, C.P. 6128 succursale Centre-ville, Montréal, Québec, Canada H3C 3J7. TEL.: 1 (514) 343-6111, ext. 1814; FAX: 1 (514) 343 5831. E-mail: jouinit@magellan.umontreal.ca
} 


\section{Contents}

List of assumptions, propositions and theorems iii

$\begin{array}{ll}\text { 1. Introduction } & 1\end{array}$

2. Framework 3

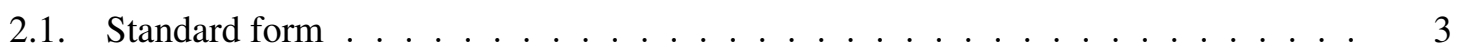

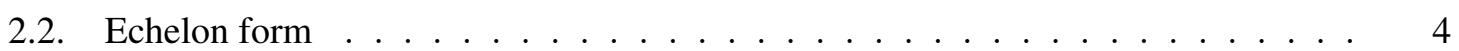

2.3. Regularity assumptions . . . . . . . . . . . . . . . . 8

3. Two-step linear estimation 9

$\begin{array}{llr}\text { 4. Asymptotic distribution } & 12\end{array}$

$\begin{array}{lll}\text { 5. Conclusion } & 15\end{array}$

$\begin{array}{ll}\text { A. Appendix: Proofs } & 17\end{array}$

\section{List of assumptions, propositions and theorems}

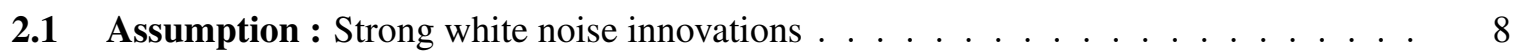

2.2 Assumption : Uniform boundedness of fourth moments . . . . . . . . . . . 8

2.3 Assumption : Autoregressive truncation lag of order less than $T^{1 / 2} \ldots \ldots \ldots$

2.4 Assumption : Decay rate of truncated autoregressive coefficients . . . . . . . . . . 9

2.5 Assumption : Autoregressive truncation lag of order less than $T^{1 / 4} \ldots \ldots \ldots$

3.1 Proposition : Innovation covariance estimator consistency . . . . . . . . . . . 11

4.1 Theorem : Consistency of second step HR estimates . . . . . . . . . . . . . . . . 14

4.2 Proposition : Asymptotic equivalence . . . . . . . . . . . . . . . . . . . 14

4.3 Theorem : Asymptotic distribution of two-stage estimator . . . . . . . . . . . . . 14

Proof of Proposition $3.1 \ldots \ldots \ldots \ldots$

Proof of Proposition $4.1 \ldots \ldots \ldots \ldots$

Proof of Theorem $4.1 \ldots \ldots \ldots \ldots$

Proof of Proposition $4.2 \ldots \ldots \ldots \ldots \ldots$

Proof of Theorem $4.3 \ldots \ldots \ldots \ldots \ldots$ 


\section{Introduction}

Multivariate time series analysis is widely based on vector autoregressive models (VAR), especially in econometric studies [see Lütkepohl $(1991,2001)$ and Hamilton (1994, Chapter 11)]. One reason for this popularity is that VAR models are easy to estimate and can account for relatively complex dynamic phenomena. On the other hand, very large numbers of parameters are often required to obtain a good fit, and the class of VAR models is not robust to disaggregation: if a vector process satisfies a VAR scheme, its subvectors (such as individual components) do not follow VAR processes. Instead, the subvectors of VAR processes follow vector autoregressive moving average (VARMA) processes. The latter class, indeed, includes VAR models as a special case, and can reproduce in a parsimonious way a much wider class of autocovariance structures. So they can lead to improvements in estimation and forecast precision. Further, VARMA modelling is theoretically consistent, in the sense that the subvectors of a VARMA model also satisfy VARMA schemes (usually of different order). Similarly, the VARMA class of models is not affected by temporal aggregation, while a VAR model may cease to be a VAR after it has been aggregated over time [see Lütkepohl (1987)].

VARMA modelling has been proposed a long time ago [see Hillmer and Tiao (1979), Tiao and Box (1981), Lütkepohl (1991), Boudjellaba, Dufour and Roy (1992, 1994), Reinsel (1997)], but has remained little used in practical work. Although the process of building VARMA models is, in principle, similar to the one associated with univariate ARMA modelling, the difficulties involved are compounded by the multivariate nature of the data.

At the specification level, new identification issues (beyond the possible presence of common factors) arise and must be taken into account to ensure that unique parameter values can be associated with a given autocovariance structure (compatible with a VARMA model); see Hannan (1969, 1970, 1976b, 1979), Deistler and Hannan (1981), Hannan and Deistler (1988, Chapter 2), Lütkepohl (1991, Chapter 7) and Reinsel (1997, Chapter 3). An important finding of this work is the importance of the concepts of dynamic dimension and Kronecker indices in the formulation of identifiable VARMA structures. Further, specifying such models involves the selection of several autoregressive and moving average orders: in view of achieving both identifiability and efficiency, it is important that a reasonably parsimonious model be formulated. Several methods for that purpose have been proposed. The main ones include: (1) techniques based on canonical variate analysis [Akaike (1976), Cooper and Wood (1982), Tiao and Tsay (1985, 1989), Tsay (1989a)]; (2) methods which specify an echelon form through the estimation of Kronecker indices [Hannan and Kavalieris (1984b), Tsay (1989b), Nsiri and Roy (1992, 1996), Poskitt (1992), Lütkepohl and Poskitt (1996), Bartel and Lütkepohl (1998)]; (3) scalar-component models [Tiao and Tsay (1989), Tsay (1991)].

At the estimation level, once an identifiable specification has been formulated, the most widely proposed estimation method is maximum likelihood (ML) derived under the assumption of i.i.d. (independent and identically distributed) Gaussian innovations; see Hillmer and Tiao (1979), Tiao and Box (1981), Shea (1989), Mauricio (2002), and the review of Mélard, Roy and Saidi (2002). This is mainly due to the presence of a moving average part in the model, which makes the latter fundamentally nonlinear. For example, in the Gaussian case, maximizing the likelihood function of a $\operatorname{VARMA}(p, q)$ model is typically a burdensome numerical exercise, as soon as the model includes a moving average part. Even numerical convergence may be problematic. Note also that, in the 
case of weak white noise innovations, quasi-maximum likelihood estimates may not be consistent. These problems also show up (at a smaller scale) in the estimation of univariate ARMA models.

From the viewpoint of making VARMA modelling, it appears crucial to have estimation methods that are both quick and simple to implement with standard statistical software, even if this may involve an efficiency cost. Another reason for putting a premium on such estimation methods is that large-sample distributional theory tends to be quite unreliable in high-dimensional dynamic models, so that tests and confidence sets based on asymptotic approximations are also unreliable (for example, the actual size of test procedures may be far larger than their nominal size). This suggests that simulation-based procedures - for example, bootstrap techniques - should be used, but simulation may be impractical if calculation of the estimators involved is difficult or time consuming.

In the case of univariate ARMA models, a relatively simple estimation procedure was originally proposed by Hannan and Rissanen (1982); see also Durbin (1960), Hannan and Kavalieris (1984a), Zhao-Guo (1985), Hannan, Kavalieris and Mackisack (1986), Poskitt (1987), Koreisha and Pukkila (1990a, 1990b, 1995), Pukkila, Koreisha and Kallinen (1990) and Galbraith and Zinde-Walsh (1994, 1997). This approach is based on estimating (by least squares) the innovations of the process through a long autoregression; after that, the lagged innovations are replaced by the corresponding residuals in the ARMA equation, which may then be also estimated by least squares.

Extensions of this method to VARMA models have been studied by Hannan and Kavalieris (1984b, 1986), Hannan and Deistler (1988), Koreisha and Pukkila (1989), Huang and Guo (1990), Poskitt (1992), Poskitt and Lütkepohl (1995), Lütkepohl and Poskitt (1996), Lütkepohl and Claessen (1997) and Flores de Frutos and Serrano (2002). Work on VARMA estimation has focused on preliminary use of such linear estimators for model selection purposes. It is then suggested that other estimation procedures (such as ML) be used. Although consistency is proved, the asymptotic distribution of the basic two-step estimator has not apparently been supplied.

In this paper, we consider the problem of estimating the parameters of stationary VARMA models in echelon form using only linear least squares methods. The echelon form is selected because it tends to deliver relatively parsimonious parameterizations. In particular, we study a simple twostep estimator that can be implemented only through single equation linear regressions and thus is remarkably simple to apply. Such an estimator was previously considered in the above mentioned work on linear VARMA estimation, but its asymptotic distribution has not apparently been established. Given the Kronecker indices of the VARMA process, we derive the asymptotic distribution of this estimator under standard regularity conditions. In particular, we show that the latter has an asymptotic normal distribution (which entails its consistency), and we provide a simple consistent estimator for its asymptotic covariance matrix, so that asymptotically valid tests and confidence tests can be built for the parameters of the model.

The paper is organized as follows. In section 2, we formulate the background model, where the echelon form VARMA representation is considered to ensure unique parametrization, and we define the assumptions which will be used in the rest of the paper. The two-step linear estimation procedure studied in the paper is described in section 3, and we derive its asymptotic distribution in section 4. We conclude in section 5. The proofs of the propositions and theorems appear in the Appendix. 


\section{Framework}

In this section, we describe the theoretical framework and the assumptions we will consider in the sequel. We will first define the standard VARMA representation. As the latter may involve identification problems, we will then define the echelon form on the VARMA model, which ensures uniqueness of model parameters. Finally, we shall formulate the basic regularity assumptions we shall consider.

\subsection{Standard form}

A $k$-dimensional regular vector process $\left\{Y_{t}: t \in \mathbb{Z}\right\}$ has a $\operatorname{VARMA}(p, q)$ representation if it satisfies an equation of the form:

$$
Y_{t}=\sum_{i=1}^{p} A_{i} Y_{t-i}+u_{t}+\sum_{j=1}^{q} B_{j} u_{t-j},
$$

for all $t$, where $Y_{t}=\left(Y_{1, t}, \ldots, Y_{k, t}\right)^{\prime}, p$ and $q$ are non-negative integers (respectively, the autoregressive and moving average orders), $A_{i}$ and $B_{j}$ the $k \times k$ coefficient matrices, and $\left\{u_{t}: t \in \mathbb{Z}\right\}$ is a (second order) white noise $W N\left[0, \Sigma_{u}\right]$, where $\Sigma_{u}$ is a $k \times k$ positive definite symmetric matrix. Under the stationary and invertibility conditions the coefficients $A_{i}$ and $B_{j}$ satisfy the constraints

$$
\operatorname{det}\{A(z)\} \neq 0 \text { and } \operatorname{det}\{B(z)\} \neq 0 \text { for all }|z| \leq 1
$$

where $z$ is a complex number, $A(z)=I_{k}-\sum_{i=1}^{p} A_{i} z^{i}$ and $B(z)=I_{k}+\sum_{j=1}^{q} B_{j} z^{j}$. This process has the following autoregressive and moving average representations:

$$
\begin{gathered}
Y_{t}=\sum_{\tau=1}^{\infty} \Pi_{\tau} Y_{t-\tau}+u_{t}, \\
Y_{t}=u_{t}+\sum_{\tau=1}^{\infty} \Psi_{\tau} u_{t-\tau}, t=1, \ldots, T,
\end{gathered}
$$

where

$$
\begin{aligned}
\Pi(z) & =B(z)^{-1} A(z)=I_{k}-\sum_{\tau=1}^{\infty} \Pi_{\tau} z^{\tau}, \\
\Psi(z) & =A(z)^{-1} B(z)=I_{k}+\sum_{\tau=1}^{\infty} \Psi_{\tau} z^{\tau}, \\
\operatorname{det}\{\Pi(z)\} & \neq 0 \text { and } \operatorname{det}\{\Psi(z)\} \neq 0, \text { for all }|z| \leq 1 .
\end{aligned}
$$

Note also that we can find real constants $C>0$ and $\rho \in(0,1)$ such that

$$
\left\|\Pi_{\tau}\right\| \leq C \rho^{\tau} \text { and }\left\|\Psi_{\tau}\right\| \leq C \rho^{\tau}
$$


hence

$$
\sum_{\tau=1}^{\infty}\left\|\Pi_{\tau}\right\|<\infty, \quad \sum_{\tau=1}^{\infty}\left\|\Psi_{\tau}\right\|<\infty,
$$

where $\|$.$\| is the Schur norm for a matrix [see Horn and Johnson (1985, section 5.6)], i.e.$

$$
\|M\|^{2}=\operatorname{tr}\left(M^{\prime} M\right)
$$

\subsection{Echelon form}

It is well known that the standard $\operatorname{VARMA}(p, q)$ representation given by (2.1) is not unique, in the sense that different sets of coefficients $A_{i}$ and $B_{j}$ may represent the same autocovariance structure. To ensure a unique parameterization, we shall consider the stationary invertible $\operatorname{VARMA}(p, q)$ process in echelon form representation. Such a representation can be defined as follows:

$$
\begin{gathered}
\Phi(L) Y_{t}=\Theta(L) u_{t}, \\
\Phi(L)=\Phi_{0}-\sum_{i=1}^{\bar{p}} \Phi_{i} L^{i}, \quad \Theta(L)=\Theta_{0}+\sum_{j=1}^{\bar{p}} \Theta_{j} L^{j},
\end{gathered}
$$

where $L$ denotes the lag operator, $\Phi_{i}=\left[\phi_{l m, i}\right]_{l, m=1, \ldots, k}$ and $\Theta_{j}=\left[\theta_{l m, j}\right]_{l, m=1, \ldots, k}, \bar{p}=$ $\max (p, q), \Theta_{0}=\Phi_{0}$, and $\Phi_{0}$ is a lower-triangular matrix whose diagonal elements are all equal to one. The VARMA representation (2.11) has an echelon form if $\Phi(L)=\left[\phi_{l m}(L)\right]_{l, m=1, \ldots, k}$ and $\Theta(L)=\left[\theta_{l m}(L)\right]_{l, m=1, \ldots, k}$ satisfy the following conditions: given a vector of orders $\left(p_{1}, \ldots, p_{k}\right)$ called the Kronecker indices, the operators $\phi_{l m}(L)$ and $\theta_{l m}(L)$ on any given row $l$ of $\Phi(L)$ and $\Theta(L)$ have the same degree $p_{l}(1 \leq l \leq k)$ and

$$
\begin{aligned}
\phi_{l m}(L) & =1-\sum_{i=1}^{p_{l}} \phi_{l l, i} L^{i} \quad \text { if } l=m, \\
& =-\sum_{i=p_{l}-p_{l m}+1}^{p_{l}} \phi_{l m, i} L^{i} \quad \text { if } l \neq m, \\
\theta_{l m}(L) & =\sum_{j=0}^{p_{l}} \theta_{l m, j} L^{j} \quad \text { with } \Theta_{0}=\Phi_{0},
\end{aligned}
$$

for $l, m=1, \ldots, k$, where

$$
\begin{aligned}
p_{l m} & =\min \left(p_{l}+1, p_{m}\right) & & \text { for } l \geq m, \\
& =\min \left(p_{l}, p_{m}\right) & & \text { for } l<m .
\end{aligned}
$$

Clearly, $p_{l l}=p_{l}$ is the order of the polynomial (i.e., the number of free coefficients) on the $l$-th diagonal element of $\Phi(L)$ as well as the order of the polynomials on the corresponding row of $\Theta(L)$, while $p_{l m}$ specifies the number of free coefficients in the operator $\phi_{l m}(L)$ for $l \neq m$. The sum of the Kronecker indices $\sum_{l=1}^{k} p_{l}$ is called the McMillan degree. The $P$ matrix formed by the Kro- 
necker indices associated with the model is $P=\left[p_{l m}\right]_{l, m=1, \ldots, k}$. This leads to $\sum_{l=1}^{k} \sum_{m=1}^{k} p_{l m}$ autoregressive and $k \sum_{l=1}^{k} p_{l}$ moving average free coefficients, respectively. Obviously, for the VARMA orders we have $\bar{p}=\max \left(p_{1}, \ldots, p_{k}\right)$. Note that this identified parameterization for $\operatorname{VARMA}(p, q)$ models ensures the uniqueness of left-coprime operators $\Phi(L)$ and $\Theta(L)$. Although other identifiable parameterizations could be used - such as the final equations form - the echelon form tends to be more parsimonious and can lead to efficiency gains. For proofs of the uniqueness of the echelon form and for other identification conditions, the reader should consult to Hannan (1969, 1970, 1976a, 1979), Deistler and Hannan (1981), Hannan and Deistler (1988) and Lütkepohl (1991, Chapter 7).

The stationarity and invertibility conditions for echelon form of (2.11) are the same as usual, namely

$$
\operatorname{det}\{\Phi(z)\} \neq 0 \text { for all }|z| \leq 1 \text {, }
$$

for stationarity, and

$$
\operatorname{det}\{\Theta(z)\} \neq 0 \text { for all }|z| \leq 1 \text {, }
$$

for invertibility, where

$$
\Phi(z)=\Phi_{0}-\sum_{i=1}^{\bar{p}} \Phi_{i} z^{i}, \quad \Theta(z)=\Theta_{0}+\sum_{j=1}^{\bar{p}} \Theta_{j} z^{j},
$$

with $\Pi(z)=\Theta(z)^{-1} \Phi(z)$ and $\Psi(z)=\Phi(z)^{-1} \Theta(z)$. It will be useful to observe that (2.11) can be rewritten in the following form:

$$
Y_{t}=\left(I_{k}-\Phi_{0}\right) V_{t}+\sum_{i=1}^{\bar{p}} \Phi_{i} Y_{t-i}+\sum_{j=1}^{\bar{p}} \Theta_{j} u_{t-j}+u_{t}
$$

where

$$
V_{t}=Y_{t}-u_{t}=\Phi_{0}^{-1}\left[\sum_{i=1}^{\bar{p}} \Phi_{i} Y_{t-i}+\sum_{j=1}^{\bar{p}} \Theta_{j} u_{t-j}\right] .
$$

Note that $V_{t}$ is a function of lagged values of $Y_{t}$ and $u_{t}$, so that the error term $u_{t}$ in (2.19) is uncorrelated with all the other variables on the right-hand side of the equation.

Set

$$
\begin{aligned}
X_{t} & =\left[V_{t}^{\prime}, Y_{t-1}^{\prime}, \ldots, Y_{t-\bar{p}}^{\prime}, u_{t-1}^{\prime}, \ldots, u_{t-\bar{p}}^{\prime}\right]^{\prime}, \\
D & =\left[I_{k}-\Phi_{0}, \Phi_{1}, \ldots, \Phi_{\bar{p}}, \Theta_{1}, \ldots, \Theta_{\bar{p}}\right]^{\prime} .
\end{aligned}
$$

The vector $X_{t}$ has dimension $(k h) \times 1$ where $h=2 \bar{p}+1$ while $D$ is a $(k h) \times k$ matrix of coefficients. In view of (2.20), it is clear the covariance matrix of $X_{t}$ is singular, so it is crucial that (identifying) restrictions be imposed on model coefficients. Under the restrictions of the echelon form (2.12) (2.15), we can find a unique $\left(k^{2} h\right) \times \nu$ full rank matrix $R$ such that $\beta=R \eta$, where $\eta$ is a $\nu \times 1$ 
vector of free coefficients and $\nu<k^{2} h$. Thus $Y_{t}$ in (2.19) can be expressed as

$$
Y_{t}=D^{\prime} X_{t}+u_{t}=\left(I_{k} \otimes X_{t}^{\prime}\right) R \eta+u_{t} .
$$

The structure of $R$ is such that

$$
\begin{gathered}
\beta=\operatorname{vec}(D)=R \eta \\
R=\operatorname{diag}\left(R_{1}, \ldots, R_{k}\right)=\left[\begin{array}{cccc}
R_{1} & 0 & \cdots & 0 \\
0 & R_{2} & \cdots & \vdots \\
\vdots & \vdots & & 0 \\
0 & 0 & \cdots & R_{k}
\end{array}\right],
\end{gathered}
$$

where $R_{i}, i=1,2, \ldots, k$, are $(k h) \times \nu_{i}$ full-rank selection (zero-one) matrices, each one of which selects the non-zero elements of the corresponding equation, and $\nu_{i}$ is the number of freely varying coefficients present in the $i$-th equation. The structure of $R_{i}$ is such that $R_{i}^{\prime} R_{i}=I_{\nu_{i}}$ and $\beta_{i}=R_{i} \eta_{i}$ where $\beta_{i}$ and $\eta_{i}$ are respectively a $(k h) \times 1$ and $\nu_{i} \times 1$ vectors so that $\beta_{i}$ is the unconstrained parameter vector in the $i$-th equation of (2.19) - on which zero restrictions are imposed - and $\eta_{i}$ is the corresponding vector of free parameters:

$$
\beta=\left(\beta_{1}^{\prime}, \beta_{2}^{\prime}, \ldots, \beta_{k}^{\prime}\right)^{\prime}, \quad \eta=\left(\eta_{1}^{\prime}, \eta_{2}^{\prime}, \ldots, \eta_{k}^{\prime}\right)^{\prime} .
$$

Note also that successful identification entails that

$$
\operatorname{rank}\left\{\mathrm{E}\left[R^{\prime}\left(I_{k} \otimes X_{t}\right)\left(I_{k} \otimes X_{t}^{\prime}\right) R\right]\right\}=\operatorname{rank}\left\{R^{\prime}\left(I_{k} \otimes \Gamma\right) R\right\}=\nu
$$

where $\Gamma=\mathrm{E}\left(X_{t} X_{t}^{\prime}\right)$, or equivalently

$$
\operatorname{rank}\left\{\mathrm{E}\left[R_{i}^{\prime} X_{t} X_{t}^{\prime} R_{i}\right]\right\}=\operatorname{rank}\left\{R_{i}^{\prime} \Gamma R_{i}\right\}=\nu_{i}, \quad i=1, \ldots, k .
$$

Setting

$$
\begin{aligned}
X(T) & =\left[X_{1}, \ldots, X_{T}\right]^{\prime}, \\
Y(T) & =\left[Y_{1}, \ldots, Y_{T}\right]^{\prime}=\left[y_{1}(T), \ldots, y_{k}(T)\right], \\
U(T) & =\left[u_{1}, \ldots, u_{T}\right]^{\prime}=\left[U_{1}(T), \ldots, U_{k}(T)\right], \\
y(T) & =\operatorname{vec}[Y(T)], \quad u(T)=\operatorname{vec}[U(T)],
\end{aligned}
$$

(2.23) can be put in any one of the two following matrix forms:

$$
\begin{aligned}
Y(T) & =X(T) D+U(T), \\
y(T) & =\left[I_{k} \otimes X(T)\right] R \eta+u(T),
\end{aligned}
$$


where $\left[I_{k} \otimes X(T)\right] R$ is a $(k T) \times \nu$ matrix. In the sequel, we shall assume that

$$
\operatorname{rank}\left(\left[I_{k} \otimes X(T)\right] R\right)=\nu \text { with probability } 1 .
$$

Under the assumption that the process is a regular process with continuous distribution, it is easy that the latter must hold.

To see better how the echelon restrictions should be written, consider the following $\operatorname{VARMA}(2,1)$ model in echelon form:

$$
\begin{aligned}
& Y_{1, t}=\phi_{11,1} Y_{1, t-1}+\phi_{11,2} Y_{1, t-2}+u_{1, t} \\
& Y_{2, t}=\phi_{21,0}\left(Y_{1, t}-u_{1, t}\right)+\phi_{21,1} Y_{1, t-1}+\phi_{22,1} Y_{2, t-1}+\theta_{22,1} u_{2, t-1}+u_{2, t} .
\end{aligned}
$$

In this case, we have:

$$
\begin{aligned}
\Phi(L) & =\left[\begin{array}{cc}
1-\phi_{11,1} L-\phi_{11.2} L^{2} & -\phi_{12,2} L^{2} \\
-\phi_{21,0}-\phi_{21,1} L & 1-\phi_{22,1} L
\end{array}\right], \\
\Theta(L) & =\left[\begin{array}{cc}
1+\theta_{11,1} L+\theta_{11,2} L^{2} & \theta_{12,1} L+\theta_{12,2} L^{2} \\
\theta_{21,1} L & 1+\theta_{22,1} L
\end{array}\right],
\end{aligned}
$$

with $\phi_{12,2}=0, \theta_{11,1}=0, \theta_{11,2}=0, \theta_{12,1}=0, \theta_{12,2}=0, \theta_{21,1}=0$, so that the Kronecker indices are $p_{1}=p_{11}=2, p_{2}=p_{22}=1, p_{21}=2$ and $p_{12}=1$. Setting $X_{t}=\left[V_{t}^{\prime}, Y_{t-1}^{\prime}, Y_{t-2}^{\prime}, u_{t-1}^{\prime}\right]^{\prime}$, $V_{t}=\left(V_{1, t}, V_{2, t}\right)^{\prime}, V_{1, t}=\left(Y_{1, t}-u_{1, t}\right)$ and $V_{2, t}=\left(Y_{2, t}-u_{2, t}\right)$, we can then write:

$$
\begin{aligned}
{\left[\begin{array}{l}
Y_{1, t} \\
Y_{2, t}
\end{array}\right]=} & {\left[\begin{array}{cc}
0 & 0 \\
\phi_{21,0} & 0
\end{array}\right]\left[\begin{array}{l}
V_{1, t} \\
V_{2, t}
\end{array}\right]+\left[\begin{array}{cc}
\phi_{11,1} & 0 \\
\phi_{21,1} & \phi_{22,1}
\end{array}\right]\left[\begin{array}{l}
Y_{1, t-1} \\
Y_{2, t-1}
\end{array}\right] } \\
& +\left[\begin{array}{cc}
\phi_{11,2} & 0 \\
0 & 0
\end{array}\right]\left[\begin{array}{l}
Y_{1, t-2} \\
Y_{2, t-2}
\end{array}\right]+\left[\begin{array}{cc}
0 & 0 \\
0 & \theta_{22,1}
\end{array}\right]\left[\begin{array}{l}
u_{1, t-1} \\
u_{2, t-1}
\end{array}\right]+\left[\begin{array}{l}
u_{1, t} \\
u_{2, t}
\end{array}\right] .
\end{aligned}
$$

Here we have:

$$
\begin{gathered}
\beta=\left(0,0, \phi_{11,1}, 0, \phi_{11,2}, 0,0,0, \phi_{21,0}, 0, \phi_{21,1}, \phi_{22,1}, 0,0,0, \theta_{22,1}\right)^{\prime}, \\
\eta=\left(\phi_{11,1}, \phi_{11,2}, \phi_{21,0}, \phi_{21,1}, \phi_{22,1}, \theta_{22,1}\right)^{\prime} \\
{\left[I_{k} \otimes X_{t}^{\prime}\right] R=\left[\begin{array}{cccccc}
Y_{1, t-1} & Y_{1, t-2} & 0 & 0 & 0 & 0 \\
0 & 0 & V_{1, t} & Y_{1, t-1} & Y_{2, t-1} & u_{2, t-1}
\end{array}\right],}
\end{gathered}
$$


and

$$
\left[I_{k} \otimes X(T)\right] R=\left[\begin{array}{cccccc}
Y_{1,0} & Y_{1,-1} & 0 & 0 & 0 & 0 \\
0 & 0 & V_{1,1} & Y_{1,0} & Y_{2,0} & u_{2,0} \\
Y_{1,1} & Y_{1,0} & 0 & 0 & 0 & 0 \\
0 & 0 & V_{1,2} & Y_{1,1} & Y_{2,1} & u_{2,1} \\
\vdots & \vdots & \vdots & \vdots & \vdots & \vdots \\
Y_{1, T-1} & Y_{1, T-2} & 0 & 0 & 0 & 0 \\
0 & 0 & V_{1, T} & Y_{1, T-1} & Y_{2, T-1} & u_{2, T-1}
\end{array}\right]
$$

The appropriate matrix $R$ is given by:

$$
R^{\prime}=\left[\begin{array}{llllllllllllllll}
0 & 0 & 1 & 0 & 0 & 0 & 0 & 0 & 0 & 0 & 0 & 0 & 0 & 0 & 0 & 0 \\
0 & 0 & 0 & 0 & 1 & 0 & 0 & 0 & 0 & 0 & 0 & 0 & 0 & 0 & 0 & 0 \\
0 & 0 & 0 & 0 & 0 & 0 & 0 & 0 & 1 & 0 & 0 & 0 & 0 & 0 & 0 & 0 \\
0 & 0 & 0 & 0 & 0 & 0 & 0 & 0 & 0 & 0 & 1 & 0 & 0 & 0 & 0 & 0 \\
0 & 0 & 0 & 0 & 0 & 0 & 0 & 0 & 0 & 0 & 0 & 1 & 0 & 0 & 0 & 0 \\
0 & 0 & 0 & 0 & 0 & 0 & 0 & 0 & 0 & 0 & 0 & 0 & 0 & 0 & 0 & 1
\end{array}\right]
$$

\subsection{Regularity assumptions}

In order to establish the asymptotic distribution of the linear estimator defined below, we will need further assumptions on the innovation process and the truncation lag of the first step autoregression. We now state the assumptions we shall consider.

Assumption 2.1 Strong White NOISE InNOVATiOns. The vectors $u_{t}, t \in \mathbb{Z}$, are independent and identically distributed (i.i.d.) with mean zero, covariance matrix $\Sigma_{u}$ and continuous distribution.

Assumption 2.2 UNIFORM BOUNDEDNESS OF FOURTH MOMENTS. There is a finite constant $m_{4}$ such that, for all $1 \leq i, j, r, s \leq k$ and for all $t$,

$$
\mathrm{E}\left|u_{i t} u_{j t} u_{r t} u_{s t}\right| \leq m_{4}<\infty .
$$

Assumption 2.3 Autoregressive trunCATION LAG OF ORDER LESS THAN $T^{1 / 2}$. $n_{T}$ is a function of $T$ such that

$$
n_{T} \rightarrow \infty \text { and } n_{T}^{2} / T \rightarrow 0 \text { as } T \rightarrow \infty
$$

and, for some $c>0$ and $0<\bar{\delta}<1 / 2$,

$$
n_{T} \geq c T^{\bar{\delta}} \text { for } T \text { sufficiently large. }
$$


Assumption 2.4 DeCAY RATE OF TRUNCATED AUtOREGRESSIVE COEFFICIENTS. The coefficients of the autoregressive (2.3) representation

$$
n_{T}^{1 / 2} \sum_{\tau=n_{T}+1}^{\infty}\left\|\Pi_{\tau}\right\| \rightarrow 0 \text { as } T \rightarrow \infty .
$$

Assumption 2.1 means that we have a strong VARMA process, while Assumption 2.2 on moments of order four will ensure the empirical autocovariances of the process have finite variances. Assumption 2.3 implies that $n_{T}$ goes to infinity at a rate slower than $T^{1 / 2}$; for example, the assumption is satisfied if $n_{T}=c T^{\delta}$ with $0<\bar{\delta} \leq \delta<1 / 2$. Assumption $\mathbf{2 . 4}$ characterizes the rate of decay of autoregressive coefficients in relation with $n_{T}$.

Although the above assumptions are sufficient to show consistency of the two-stage linear estimator, we will need another assumption to show that the asymptotic distribution is normal with a distribution which is unaffected by the use of estimated innovations.

Assumption 2.5 AUtOREgRESSIVE TRUNCATION LAG OF ORDER LESS THAN $T^{1 / 4} \cdot n_{T}$ is a function of $T$ such that

$$
n_{T} \rightarrow \infty \text { and } n_{T}^{4} / T \rightarrow 0 \text { as } T \rightarrow \infty .
$$

The latter assumption means that $n_{T}$ goes to infinity at a rate slower than $T^{1 / 4}$; for example, it is satisfied if $n_{T}=c T^{\delta}$ with $0<\bar{\delta} \leq \delta<1 / 4$. It is easy to see that the condition (2.49) entails (2.46). Finally, it is worthwhile to note that (2.48) holds for VARMA processes whenever $n_{T}=c T^{\delta}$ with $c>0$ and $\delta>0$, i.e.

$$
T^{\delta} \sum_{\tau=n_{T}+1}^{\infty}\left\|\Pi_{\tau}\right\| \rightarrow 0 \text { as } T \rightarrow \infty, \quad \text { for all } \delta>0 .
$$

This is easy to see from the exponential decay property of VARMA processes [see (2.8)].

\section{Two-step linear estimation}

In this section, we describe a simple estimation procedure for a VARMA models in echelon form with known order. The Kronecker indices characterizing the echelon form VARMA model are taken as given, and we focus our attention on the estimation of the autoregressive and moving average coefficients.

Let $\left(Y_{-n_{T}+1}, \ldots, Y_{T}\right)$ be a random sample of size $T+n_{T}$, where $n_{T}$ goes to infinity as $T$ goes to infinity. We consider first a "long" multivariate linear vector autoregression:

$$
Y_{t}=\sum_{\tau=1}^{n_{T}} \Pi_{\tau} Y_{t-\tau}+u_{t}\left(n_{T}\right), \quad t=1, \ldots, T,
$$


and the corresponding least squares estimates:

$$
\tilde{\Pi}\left(n_{T}\right)=\left[\tilde{\Pi}_{1}\left(n_{T}\right), \ldots, \tilde{\Pi}_{n_{T}}\left(n_{T}\right)\right] .
$$

Such an estimation can be performed by running $k$ separate univariate linear regressions (one for each variable in $Y_{t}$ ). Yule-Walker estimates of the corresponding theoretical coefficients $\Pi_{\tau}$ could also be considered. Then, under model (2.3) and the assumptions $\mathbf{2 . 1}$ to $\mathbf{2 . 4}$, it follows from the results of Paparoditis (1996, Theorem 2.1) and Lewis and Reinsel (1985, proof of Theorem 1) that:

$$
\left\|\tilde{\Pi}\left(n_{T}\right)-\Pi\left(n_{T}\right)\right\|=O_{p}\left(n_{T}^{1 / 2} / T^{1 / 2}\right)
$$

where

$$
\Pi\left(n_{T}\right)=\left[\Pi_{1}, \ldots, \Pi_{n_{T}}\right] .
$$

As usual, for any sequence of random variables $Z_{T}$ and positive numbers $r_{T}, T=1,2, \ldots$, the notation $Z_{T}=O_{p}\left(r_{T}\right)$ means that $Z_{T} / r_{T}$ is asymptotically bounded in probability (as $T \rightarrow \infty$ ), while $Z_{T}=o_{p}\left(r_{T}\right)$ means that $Z_{T} / r_{T}$ converges to zero in probability. When $Y_{t}$ satisfies a VARMA scheme, the assumptions $\mathbf{2 . 3}$ and $\mathbf{2 . 4}$ are satisfied by any truncation lag of the form $n_{T}=c T^{\delta}$ with $c>0$ and $0<\delta<1 / 2$. If, furthermore, the assumptions $\mathbf{2 . 3}$ and $\mathbf{2 . 4}$ are replaced by stronger ones, namely

$$
\begin{gathered}
n_{T} \rightarrow \infty \text { and } n_{T}^{3} / T \rightarrow 0 \text { as } T \rightarrow \infty, \\
T^{1 / 2} \sum_{\tau=n_{T}+1}^{\infty}\left\|\Pi_{\tau}\right\| \rightarrow 0 \text { as } T \rightarrow \infty,
\end{gathered}
$$

then asymptotic normality also holds:

$$
T^{1 / 2} l\left(n_{T}\right)^{\prime}\left[\tilde{\pi}\left(n_{T}\right)-\pi\left(n_{T}\right)\right] \underset{T \rightarrow \infty}{\longrightarrow} \mathrm{N}\left[0, l\left(n_{T}\right)^{\prime} Q\left(n_{T}\right) l\left(n_{T}\right)\right],
$$

where $l\left(n_{T}\right)$ is a sequence of $k^{2} n_{T} \times 1$ vectors such that $0<M_{1} \leq\left\|l\left(n_{T}\right)\right\| \leq M_{2}<\infty$ for $n_{T}=1,2, \ldots$, and

$$
\begin{gathered}
\tilde{\pi}\left(n_{T}\right)-\pi\left(n_{T}\right)=\operatorname{vec}\left[\tilde{\Pi}\left(n_{T}\right)-\Pi\left(n_{T}\right)\right], \\
Q\left(n_{T}\right)=\Gamma\left(n_{T}\right)^{-1} \otimes \Sigma_{u}, \Gamma\left(n_{T}\right)=\mathrm{E}\left[Y_{t}\left(n_{T}\right) Y_{t}\left(n_{T}\right)^{\prime}\right], \\
Y_{t}\left(n_{T}\right)=\left[Y_{t-1}^{\prime}, Y_{t-2}^{\prime}, \ldots, Y_{t-n_{T}}^{\prime}\right]^{\prime} .
\end{gathered}
$$

Note that a possible choice for the sequence $n_{T}$ that satisfies both $n_{T}^{3} / T \rightarrow 0$ and $T^{1 / 2} \sum_{\tau=n_{T}+1}^{\infty}\left\|\Pi_{\tau}\right\| \rightarrow 0$ is for example $n_{T}=T^{1 / \varepsilon}$ with $\varepsilon>3$. On the other hand $n_{T}=\ln (\ln T)$, as suggested by Hannan and Kavalieris (1984b), is not a permissible choice because in general $T^{1 / 2} \sum_{\tau=n_{T}+1}^{\infty}\left\|\Pi_{\tau}\right\|$ does not approach zero as $T \rightarrow \infty$. 
Let

$$
\tilde{u}_{t}\left(n_{T}\right)=Y_{t}-\sum_{\tau=1}^{n_{T}} \tilde{\Pi}_{\tau}\left(n_{T}\right) Y_{t-\tau}=Y_{t}-\tilde{\Pi}\left(n_{T}\right) Y_{t}\left(n_{T}\right)
$$

be the estimated residuals obtained from the first stage estimation procedure,

$$
\tilde{\Sigma}_{u}\left(n_{T}\right)=\frac{1}{T} \sum_{t=1}^{T} \tilde{u}_{t}\left(n_{T}\right) \tilde{u}_{t}\left(n_{T}\right)^{\prime}
$$

the corresponding estimator of the innovation covariance matrix, and

$$
\hat{\Sigma}_{T}=\frac{1}{T} \sum_{t=1}^{T} u_{t} u_{t}^{\prime}
$$

the covariance "estimator" based on the true innovations. Then, we have the following equivalences and convergences.

Proposition 3.1 InNOVATION COVARIANCE ESTIMATOR CONSISTENCy. Let $\left\{Y_{t}: t \in \mathbb{Z}\right\}$ be a $k$-dimensional stationary invertible stochastic process with the VARMA echelon representation given by (2.11) - (2.15). Then, under the assumptions $\mathbf{2 . 1}$ to 2.4, we have:

$$
\begin{gathered}
\left\|\frac{1}{T} \sum_{t=1}^{T} u_{t}\left[\tilde{u}_{t}\left(n_{T}\right)-u_{t}\right]^{\prime}\right\|=O_{p}\left(\frac{n_{T}}{T}\right) \\
\frac{1}{T} \sum_{t=1}^{T}\left\|\tilde{u}_{t}\left(n_{T}\right)-u_{t}\right\|^{2}=O_{p}\left(\frac{n_{T}^{2}}{T}\right) \\
\left\|\frac{1}{T} \sum_{t=1}^{T}\left[\tilde{u}_{t}\left(n_{T}\right)-u_{t}\right]\left[\tilde{u}_{t}\left(n_{T}\right)-u_{t}\right]^{\prime}\right\|=O_{p}\left(\frac{n_{T}^{2}}{T}\right), \\
\left\|\tilde{\Sigma}_{u}\left(n_{T}\right)-\hat{\Sigma}_{T}\right\|=O_{p}\left(\frac{n_{T}^{2}}{T}\right), \quad\left\|\tilde{\Sigma}_{u}\left(n_{T}\right)-\Sigma_{u}\right\|=O_{p}\left(\frac{n_{T}^{2}}{T}\right) .
\end{gathered}
$$

The asymptotic equivalence between $\tilde{u}_{t}\left(n_{T}\right)$ and $u_{t}$ stated in the above proposition suggests we may be able to consistently estimate the parameters of the VARMA model in (2.19) after replacing the unobserved lagged innovations $u_{t-1}, \ldots, u_{t-\bar{p}}$ with the corresponding residuals $\tilde{u}_{t-1}\left(n_{T}\right), \ldots, \tilde{u}_{t-\bar{p}}\left(n_{T}\right)$ from the above long autoregression. So, in order to estimate the coefficients $\Phi_{i}$ and $\Theta_{j}$ of the VARMA process, we consider a linear regression of the form

$$
Y_{t}=\sum_{i=1}^{\bar{p}} \Phi_{i} Y_{t-i}+\sum_{j=1}^{\bar{p}} \Theta_{j} \tilde{u}_{t-j}\left(n_{T}\right)+e_{t}\left(n_{T}\right)
$$


imposing the (exclusion) restrictions associated with the echelon form. Setting

$$
\tilde{V}_{t}\left(n_{T}\right)=Y_{t}-\tilde{u}_{t}\left(n_{T}\right)
$$

this regression can also be put in a regression form similar to (2.19):

$$
Y_{t}=\left(I_{k}-\Phi_{0}\right) \tilde{V}_{t}\left(n_{T}\right)+\sum_{i=1}^{\bar{p}} \Phi_{i} Y_{t-i}+\sum_{j=1}^{\bar{p}} \Theta_{j} \tilde{u}_{t-j}\left(n_{T}\right)+e_{t}\left(n_{T}\right)
$$

where

$$
e_{t}\left(n_{T}\right)=\tilde{u}_{t}\left(n_{T}\right)+\sum_{j=0}^{\bar{p}} \Theta_{j}\left[u_{t-j}-\tilde{u}_{t-j}\left(n_{T}\right)\right] .
$$

Note that (3.20) can be written as

$$
Y_{t}=\left[I_{k} \otimes \tilde{X}_{t}\left(n_{T}\right)^{\prime}\right] R \eta+e_{t}\left(n_{T}\right), \quad t=1, \ldots, T,
$$

where

$$
\tilde{X}_{t}\left(n_{T}\right)=\left[\tilde{V}_{t}\left(n_{T}\right)^{\prime}, Y_{t-1}^{\prime}, \ldots, Y_{t-\bar{p}}^{\prime}, \tilde{u}_{t-1}\left(n_{T}\right)^{\prime}, \ldots, \tilde{u}_{t-\bar{p}}\left(n_{T}\right)^{\prime}\right]^{\prime} .
$$

Therefore the second step estimators $\tilde{\eta}$ can be obtained by running least squares on the equations (3.22). Setting

$$
\tilde{X}\left(n_{T}\right)=\left[\tilde{X}_{1}\left(n_{T}\right), \tilde{X}_{2}\left(n_{T}\right), \ldots, \tilde{X}_{T}\left(n_{T}\right)\right]^{\prime}
$$

we get, after some manipulations,

$$
\begin{aligned}
\tilde{\eta} & =\left\{R^{\prime}\left[I_{k} \otimes \tilde{X}\left(n_{T}\right)^{\prime} \tilde{X}\left(n_{T}\right)\right] R\right\}^{-1} R^{\prime}\left[I_{k} \otimes \tilde{X}\left(n_{T}\right)^{\prime}\right] y(T) \\
& =\left(\tilde{\eta}_{1}^{\prime}, \tilde{\eta}_{2}^{\prime}, \ldots, \tilde{\eta}_{k}^{\prime}\right)^{\prime}
\end{aligned}
$$

where

$$
\tilde{\eta}_{i}=\left[R_{i}^{\prime} \tilde{X}\left(n_{T}\right)^{\prime} \tilde{X}\left(n_{T}\right) R_{i}\right]^{-1} R_{i}^{\prime} \tilde{X}\left(n_{T}\right)^{\prime} y_{i}(T) .
$$

$\tilde{\eta}$ can be easily obtained by stacking the single equation $L S$ estimators $\tilde{\eta}_{i}$ which are obtained by regressing $y_{i}$ on $\tilde{X}\left(n_{T}\right) R_{i}$.

\section{Asymptotic distribution}

We will now study the asymptotic distribution of the linear estimator described in the previous section. For that purpose, we note first that the estimator $\tilde{\eta}$ in (3.25) can be expressed as

$$
\left.\tilde{\eta}=\left\{R^{\prime}\left[I_{k} \otimes \tilde{\Gamma}\left(n_{T}\right)\right]\right\} R\right\}^{-1}\left\{\frac{1}{T} \sum_{t=1}^{T} R^{\prime}\left[I_{k} \otimes \tilde{X}_{t}\left(n_{T}\right)\right] Y_{t}\right\}
$$


where

$$
\tilde{\Gamma}\left(n_{T}\right)=\frac{1}{T} \sum_{t=1}^{T} \tilde{X}_{t}\left(n_{T}\right) \tilde{X}_{t}\left(n_{T}\right)^{\prime} .
$$

Let also

$$
\begin{aligned}
& \tilde{\Upsilon}\left(n_{T}\right)=I_{k} \otimes \tilde{\Gamma}\left(n_{T}\right), \quad \tilde{Q}\left(n_{T}\right)=\left[R^{\prime} \tilde{\Upsilon}\left(n_{T}\right) R\right]^{-1}, \\
& \tilde{\Omega}\left(n_{T}\right)=\frac{1}{T} \sum_{t=1}^{T} R^{\prime}\left[I_{k} \otimes \tilde{X}_{t}\left(n_{T}\right)\right] e_{t}\left(n_{T}\right) .
\end{aligned}
$$

It is then easy to see that

$$
\tilde{\eta}-\eta=\tilde{Q}\left(n_{T}\right) \tilde{\Omega}\left(n_{T}\right)
$$

hence

$$
\|\tilde{\eta}-\eta\| \leq\left\|\tilde{Q}\left(n_{T}\right)\right\|_{1}\left\|\tilde{\Omega}\left(n_{T}\right)\right\| \leq\left\|\tilde{Q}\left(n_{T}\right)\right\|\left\|\tilde{\Omega}\left(n_{T}\right)\right\|
$$

where $\|A\|_{1}=\sup _{x \neq 0}\left\{\frac{\|A x\|}{\|x\|}\right\}$ stands for the largest eigenvalue of $A^{\prime} A$ and we used the inequality $\|A B\|^{2} \leq\|A\|_{1}^{2}\|B\|^{2}$ for any two conformable matrices $A$ and $B$ [see Horn and Johnson (1985, section 5.6)].

Define

$$
\begin{aligned}
\Gamma & =\mathrm{E}\left(X_{t} X_{t}^{\prime}\right), \quad \Upsilon=I_{k} \otimes \Gamma, \quad Q=\left(R^{\prime} \Upsilon R\right)^{-1}, \\
\Gamma_{T} & =\frac{1}{T} \sum_{t=1}^{T} X_{t} X_{t}^{\prime}, \quad \Upsilon_{T}=I_{k} \otimes \Gamma_{T}=\frac{1}{T} \sum_{t=1}^{T} I_{k} \otimes X_{t} X_{t}^{\prime}, \\
Q_{T} & =\left(R^{\prime} \Upsilon_{T} R\right)^{-1}, \quad \Omega_{T}=\frac{1}{T} \sum_{t=1}^{T} R^{\prime}\left(I_{k} \otimes X_{t}\right) u_{t} .
\end{aligned}
$$

Note that $R^{\prime} \Upsilon R$ is positive definite by the regularity assumption. To study the convergence and distributional properties of $\tilde{\eta}-\eta$, we need first to establish the following proposition.

Proposition 4.1 Let $\left\{Y_{t}: t \in \mathbb{Z}\right\}$ be a $k$-dimensional stationary invertible stochastic process with the VARMA echelon representation given by (2.11) - (2.15). Then, under the assumptions $\mathbf{2 . 1}$ to 2.4, we have the following equivalences:

$$
\begin{gathered}
\frac{1}{T}\left\|\tilde{X}\left(n_{T}\right)-X(T)\right\|^{2}=O_{p}\left(\frac{n_{T}^{2}}{T}\right), \\
\left\|\tilde{\Gamma}\left(n_{T}\right)-\Gamma_{T}\right\|=O_{p}\left(\frac{n_{T}}{T^{1 / 2}}\right) \\
\left\|\tilde{\Upsilon}\left(n_{T}\right)-\Upsilon_{T}\right\|=O_{p}\left(\frac{n_{T}}{T^{1 / 2}}\right) \\
\left\|\tilde{Q}\left(n_{T}\right)^{-1}-Q^{-1}\right\|=O_{p}\left(\frac{n_{T}}{T^{1 / 2}}\right)
\end{gathered}
$$




$$
\left\|\tilde{Q}\left(n_{T}\right)-Q\right\|=O_{p}\left(\frac{n_{T}}{T^{1 / 2}}\right) .
$$

The latter proposition shows that the matrices $\tilde{\Gamma}\left(n_{T}\right), \tilde{\Upsilon}\left(n_{T}\right), \tilde{Q}\left(n_{T}\right)^{-1}$ and $\tilde{Q}\left(n_{T}\right)$ - based on approximate innovations (estimated from a long autoregression) - are all asymptotically equivalent to the corresponding matrices based on true innovations, according to the rate $n_{T} / T^{1 / 2}$. Similarly the norm of the difference between the approximate regressor matrix $\tilde{X}\left(n_{T}\right)$ and $X(T)$ has order $O_{p}\left(n_{T} / T^{1 / 2}\right)$. This suggests that $\tilde{\eta}$ converges to $\eta$, and we give the appropriate rate of convergence in the following theorem.

Theorem 4.1 CONSISTENCY OF SECOND STEP HR ESTIMATES. Let $\left\{Y_{t}: t \in \mathbb{Z}\right\}$ be a $k$ dimensional stationary invertible stochastic process with the VARMA echelon representation given by (2.11) - (2.15). Then, under the assumptions $\mathbf{2 . 1}$ to $\mathbf{2 . 4}$, we have

$$
\begin{aligned}
\left\|\Omega_{T}\right\| & =O_{p}\left(\frac{1}{T^{1 / 2}}\right), \quad\left\|\tilde{\Omega}\left(n_{T}\right)-\Omega_{T}\right\|=O_{p}\left(\frac{n_{T}^{2}}{T}\right), \\
\|\tilde{\eta}-\eta\| & =O_{p}\left(\frac{1}{T^{1 / 2}}\right)+O_{p}\left(\frac{n_{T}^{2}}{T}\right) .
\end{aligned}
$$

If, furthermore,

$$
n_{T}^{4} / T \rightarrow 0 \text { as } T \rightarrow \infty
$$

then

$$
\|\tilde{\eta}-\eta\|=O_{p}\left(\frac{1}{T^{1 / 2}}\right) .
$$

The latter theorem shows that $\tilde{\eta}$ is a consistent estimator. If furthermore, $n_{T}^{4} / T \rightarrow 0$ as $T \rightarrow \infty$, then $\tilde{\eta}$ converges at the rate $T^{-1 / 2}$ which is typically expected to get asymptotic normality. In order to derive an asymptotic distribution for $\tilde{\eta}$, we shall establish that the following random matrices

$$
\tilde{S}\left(n_{T}\right)=T^{1 / 2} \tilde{Q}\left(n_{T}\right) \tilde{\Omega}\left(n_{T}\right), \quad S_{T}=T^{1 / 2} Q \Omega_{T},
$$

are asymptotically equivalent.

Proposition 4.2 ASYMPTOTIC EQUIVALENCE. Let $\left\{Y_{t}: t \in \mathbb{Z}\right\}$ be a $k$-dimensional stationary invertible stochastic process with the VARMA echelon representation given by (2.11) - (2.15). Then, under the assumptions $\mathbf{2 . 1}$ to $\mathbf{2 . 4}$, the following equivalence holds

$$
\left\|\tilde{S}\left(n_{T}\right)-S_{T}\right\|=O_{p}\left(\frac{n_{T}^{2}}{T^{1 / 2}}\right) .
$$

Finally, we can give the asymptotic distribution of $\sqrt{T}(\tilde{\eta}-\eta)$.

Theorem 4.3 Asymptotic Distribution of two-STAGe estimator. Let $\left\{Y_{t}: t \in \mathbb{Z}\right\}$ be a $k$-dimensional stationary invertible stochastic process with the VARMA echelon representation 
given by (2.11) - (2.15). If the assumptions 2.1 to $\mathbf{2 . 5}$ are satisfied, then the asymptotic distribution of the estimator $\tilde{\eta}$ is the following:

$$
\sqrt{T}(\tilde{\eta}-\eta) \underset{T \rightarrow \infty}{\longrightarrow} \mathrm{N}\left[0, \Sigma_{\eta}\right]
$$

where

$$
\begin{gathered}
\Sigma_{\eta}=Q \Sigma_{X u} Q^{\prime}, \quad \Sigma_{X u}=R^{\prime}\left[\Sigma_{u} \otimes \Gamma\right] R, \\
Q=\left(R^{\prime} \Upsilon R\right)^{-1}, \quad \Upsilon=I_{k} \otimes \Gamma, \quad \Gamma=\mathrm{E}\left(X_{t} X_{t}^{\prime}\right), \\
X_{t}=\left[V_{t}^{\prime}, Y_{t-1}^{\prime}, \ldots, Y_{t-\bar{p}}^{\prime}, u_{t-1}^{\prime}, \ldots, u_{t-\bar{p}}^{\prime}\right]^{\prime} \text { and } V_{t}=Y_{t}-u_{t} .
\end{gathered}
$$

An important consequence of the above theorem is the fact that the asymptotic distribution of $\tilde{\eta}$ is the same as in the case where the innovations $u_{t-1}^{\prime}, \ldots, u_{t-\bar{p}}^{\prime}$ are known rather than approximated by a long autoregression. Furthermore, the covariance matrix $\Sigma_{\eta}$ can be consistently estimated by

$$
\hat{\Sigma}_{\eta}=\tilde{Q}\left(n_{T}\right)\left\{R^{\prime}\left[\tilde{\Sigma}_{u}\left(n_{T}\right) \otimes \tilde{\Gamma}\left(n_{T}\right)\right] R\right\} \tilde{Q}\left(n_{T}\right)^{\prime},
$$

where

$$
\begin{gathered}
\tilde{Q}\left(n_{T}\right)=\left[R^{\prime} \tilde{\Upsilon}\left(n_{T}\right) R\right]^{-1}, \quad \tilde{\Upsilon}\left(n_{T}\right)=I_{k} \otimes \tilde{\Gamma}\left(n_{T}\right), \\
\tilde{\Gamma}\left(n_{T}\right)=\frac{1}{T} \sum_{t=1}^{T} \tilde{X}_{t}\left(n_{T}\right) \tilde{X}_{t}\left(n_{T}\right)^{\prime} .
\end{gathered}
$$

Standard $t$ and $F$-type tests may then be performed in the usual way.

\section{Conclusion}

In this paper, we have provided the asymptotic distribution of a simple two-stage estimator for VARMA models in echelon form. The estimator is consistent when the auxiliary long autoregression used to generate first step estimates of model innovations has an order $n_{T}$ which increases to infinity at a rate inferior to $T^{\delta}$ with $0<\delta_{0} \leq \delta<1 / 2$. Further, it has an asymptotic normal distribution provided $n_{T}$ increases at a rate inferior to $T^{\delta}$ with $0<\delta_{0} \leq \delta<1 / 4$. In the latter case, the asymptotic distribution is not affected by the fact that estimated lagged residuals are used.

The above results can be exploited in several ways. First, the two-stage estimates and the associated distributional theory can be directly used for inference on the VARMA model. In particular, they can be used for model selection purposes and to simplify the model (e.g., by eliminating insignificant coefficients). Second, two-stage estimates can be exploited to get more efficient estimators, such as ML estimators or estimators that are asymptotically to ML. This can be done, in particular, to achieve efficiency with Gaussian innovations. Note, however, that such gains of efficiency may not obtain if the innovations are not Gaussian. Thirdly, because of its simplicity, the two-stage linear estimator is especially well adapted for being used in the context of simulationbased inference procedures, such as bootstrap tests. Further, the asymptotic distribution provided 
above can be useful in order to improve the validity of the bootstrap. Several of these issues will be studied in a subsequent paper. 


\section{A. Appendix: Proofs}

Proof of Proposition 3.1 Let us write:

$$
\left\|\tilde{\Sigma}_{u}\left(n_{T}\right)-\Sigma_{u}\right\|=\left\|\tilde{\Sigma}_{u}\left(n_{T}\right)-\hat{\Sigma}_{T}\right\|+\left\|\hat{\Sigma}_{T}-\Sigma_{u}\right\|
$$

where

$$
\begin{gathered}
\hat{\Sigma}_{T}-\Sigma_{u}=\frac{1}{T} \sum_{t=1}^{T}\left[u_{t} u_{t}^{\prime}-\Sigma_{u}\right] \\
\tilde{\Sigma}_{u}\left(n_{T}\right)-\hat{\Sigma}_{T}=\frac{1}{T} \sum_{t=1}^{T}\left\{\tilde{u}_{t}\left(n_{T}\right) \tilde{u}_{t}\left(n_{T}\right)^{\prime}-u_{t} u_{t}^{\prime}\right\} \\
=\frac{1}{T} \sum_{t=1}^{T}\left\{\left[\tilde{u}_{t}\left(n_{T}\right)-u_{t}\right] \tilde{u}_{t}\left(n_{T}\right)^{\prime}+u_{t}\left[\tilde{u}_{t}\left(n_{T}\right)-u_{t}\right]^{\prime}\right\} \\
=\frac{1}{T} \sum_{t=1}^{T}\left\{\left[\tilde{u}_{t}\left(n_{T}\right)-u_{t}\right] u_{t}^{\prime}+u_{t}\left[\tilde{u}_{t}\left(n_{T}\right)-u_{t}\right]^{\prime}+\left[\tilde{u}_{t}\left(n_{T}\right)-u_{t}\right]\left[\tilde{u}_{t}\left(n_{T}\right)-u_{t}\right]^{\prime}\right\} .
\end{gathered}
$$

By the assumptions $\mathbf{2 . 1}$ and 2.2,

$$
\begin{aligned}
\hat{\Sigma}_{T}-\Sigma_{u} & =\frac{1}{T} \sum_{t=1}^{T}\left[u_{t} u_{t}^{\prime}-\Sigma_{u}\right]=O_{p}\left(\frac{1}{T}\right), \\
\frac{1}{T} \sum_{t=1}^{T}\left\|u_{t}\right\| & =O_{p}(1), \quad \frac{1}{T} \sum_{t=1}^{T}\left\|u_{t}\right\|^{2}=O_{p}(1) .
\end{aligned}
$$

Now

$$
\tilde{u}_{t}\left(n_{T}\right)-u_{t}=\left[\Pi\left(n_{T}\right)-\tilde{\Pi}\left(n_{T}\right)\right] Y_{t}\left(n_{T}\right)+\sum_{\tau=n_{T}+1}^{\infty} \Pi_{\tau} Y_{t-\tau}
$$

hence

$$
\frac{1}{T} \sum_{t=1}^{T}\left[\tilde{u}_{t}\left(n_{T}\right)-u_{t}\right] u_{t}^{\prime}=\left[\Pi\left(n_{T}\right)-\tilde{\Pi}\left(n_{T}\right)\right] C_{Y u}\left(n_{T}\right)+S_{Y u}\left(n_{T}\right)
$$

where $Y_{t}\left(n_{T}\right)=\left[Y_{t-1}^{\prime}, \ldots, Y_{t-n_{T}}^{\prime}\right]^{\prime}$, and

$$
\begin{aligned}
C_{Y u}\left(n_{T}\right) & =\frac{1}{T} \sum_{t=1}^{T} Y_{t}\left(n_{T}\right) u_{t}^{\prime}=\left[C_{Y u}(1, T)^{\prime}, \ldots, C_{Y u}\left(n_{T}, T\right)^{\prime}\right]^{\prime}, \\
C_{Y u}(\tau, T) & =\frac{1}{T} \sum_{t=1}^{T} Y_{t-\tau} u_{t}^{\prime},
\end{aligned}
$$




$$
S_{Y u}\left(n_{T}\right)=\frac{1}{T} \sum_{t=1}^{T} \sum_{\tau=n_{T}+1}^{\infty} \Pi_{\tau} Y_{t-\tau} u_{t}^{\prime} .
$$

Using the fact that $u_{t}$ is independent of $X_{t}, u_{t-1}, \ldots, u_{1}$, we see that

$$
\begin{aligned}
\mathrm{E}\left\|C_{Y u}(\tau, T)\right\|^{2} & =\mathrm{E}\left[C_{Y u}(\tau, T) C_{Y u}(\tau, T)^{\prime}\right]=\frac{1}{T^{2}} \sum_{t=1}^{T} \mathrm{E}\left[\operatorname{tr}\left(Y_{t-\tau} u_{t}^{\prime} u_{t} Y_{t-\tau}^{\prime}\right)\right] \\
& =\frac{1}{T^{2}} \sum_{t=1}^{T} \operatorname{tr}\left[\mathrm{E}\left(u_{t}^{\prime} u_{t}\right) \mathrm{E}\left(Y_{t-\tau}^{\prime} Y_{t-\tau}\right)\right]=\frac{1}{T} \operatorname{tr}\left(\Sigma_{u}\right) \operatorname{tr}[\Gamma(0)] \\
\mathrm{E}\left[S_{Y u}\left(n_{T}\right)\right] & =0
\end{aligned}
$$

where $\Gamma(0)=\mathrm{E}\left(Y_{t} Y_{t}^{\prime}\right)$, hence

$$
\begin{aligned}
\mathrm{E}\left\|C_{Y u}\left(n_{T}\right)\right\|^{2} & =\mathrm{E}\left[C_{Y u}\left(n_{T}\right)^{\prime} C_{Y u}\left(n_{T}\right)\right]=\sum_{\tau=1}^{n_{T}} \mathrm{E}\left\|C_{Y u}(\tau, T)\right\|^{2} \\
& =\frac{n_{T}}{T} \operatorname{tr}\left(\Sigma_{u}\right) \operatorname{tr}[\Gamma(0)], \\
\sum_{\tau=1}^{n_{T}}\left\|C_{Y u}(\tau, T)\right\|^{2} & =O_{p}\left(\frac{n_{T}}{T}\right),
\end{aligned}
$$

and

$$
\left\|\left[\tilde{\Pi}\left(n_{T}\right)-\Pi\left(n_{T}\right)\right] C_{Y u}\left(n_{T}\right)\right\| \leq\left\|\tilde{\Pi}\left(n_{T}\right)-\Pi\left(n_{T}\right)\right\|\left\|C_{Y u}\left(n_{T}\right)\right\|=O_{p}\left(\frac{n_{T}}{T}\right) .
$$

Using the stationarity of $Y_{t}$ and (2.8), we have:

$$
\begin{aligned}
\mathrm{E}\left[\left\|S_{Y u}\left(n_{T}\right)\right\|\right] & \leq \mathrm{E}\left[\frac{1}{T} \sum_{t=1}^{T}\left(\sum_{\tau=n_{T}+1}^{\infty}\left\|\Pi_{\tau}\right\|\left\|Y_{t-\tau}\right\|\left\|u_{t}\right\|\right)\right] \\
& \leq\left[\mathrm{E}\left(\left\|Y_{t}\right\|^{2}\right)\right]^{1 / 2}\left[\mathrm{E}\left(\left\|u_{t}\right\|^{2}\right)\right]^{1 / 2} \frac{1}{T} \sum_{t=1}^{T} \sum_{\tau=n_{T}+1}^{\infty}\left\|\Pi_{\tau}\right\| \\
& \leq\left[\mathrm{E}\left(\left\|Y_{t}\right\|^{2}\right)\right]^{1 / 2}\left[\mathrm{E}\left(\left\|u_{t}\right\|^{2}\right)\right]^{1 / 2} \frac{C}{T} \sum_{t=1}^{T} \sum_{\tau=n_{T}+1}^{\infty} \rho^{\tau} \\
& \leq\left[\mathrm{E}\left(\left\|Y_{t}\right\|^{2}\right)\right]^{1 / 2}\left[\mathrm{E}\left(\left\|u_{t}\right\|^{2}\right)\right]^{1 / 2} \frac{C}{T} \sum_{t=1}^{T} \frac{\rho^{n_{T}+1}}{1-\rho} \\
& =\left[\mathrm{E}\left(\left\|Y_{t}\right\|^{2}\right)\right]^{1 / 2}\left[\mathrm{E}\left(\left\|u_{t}\right\|^{2}\right)\right]^{1 / 2}\left(\frac{C \rho}{1-\rho}\right) \rho^{n_{T}}=O\left(\rho^{n_{T}}\right)
\end{aligned}
$$


hence

$$
\left\|S_{Y u}\left(n_{T}\right)\right\|=O_{p}\left(\rho^{n_{T}}\right) .
$$

Consequently,

$$
\begin{aligned}
\left\|\frac{1}{T} \sum_{t=1}^{T} u_{t}\left[\tilde{u}_{t}\left(n_{T}\right)-u_{t}\right]^{\prime}\right\| & =\left\|\frac{1}{T} \sum_{t=1}^{T}\left[\tilde{u}_{t}\left(n_{T}\right)-u_{t}\right] u_{t}^{\prime}\right\| \\
& \leq\left\|\left[\tilde{\Pi}\left(n_{T}\right)-\Pi\left(n_{T}\right)\right] C_{Y u}\left(n_{T}\right)\right\|+\left\|S_{Y u}\left(n_{T}\right)\right\| \\
& =O_{p}\left(\frac{n_{T}}{T}\right),
\end{aligned}
$$

and (3.14) is established. Finally,

$$
\begin{aligned}
\left\|\frac{1}{T} \sum_{t=1}^{T}\left[\tilde{u}_{t}\left(n_{T}\right)-u_{t}\right]\left[\tilde{u}_{t}\left(n_{T}\right)-u_{t}\right]^{\prime}\right\| & \leq \frac{1}{T} \sum_{t=1}^{T}\left\|\left[\tilde{u}_{t}\left(n_{T}\right)-u_{t}\right]\left[\tilde{u}_{t}\left(n_{T}\right)-u_{t}\right]^{\prime}\right\| \\
& \leq \frac{1}{T} \sum_{t=1}^{T}\left\|\tilde{u}_{t}\left(n_{T}\right)-u_{t}\right\|^{2}
\end{aligned}
$$

where

$$
\begin{aligned}
\frac{1}{T} \sum_{t=1}^{T}\left\|\tilde{u}_{t}\left(n_{T}\right)-u_{t}\right\|^{2} \leq & \frac{3}{T} \sum_{t=1}^{T}\left\{\left\|\tilde{\Pi}\left(n_{T}\right)-\Pi\left(n_{T}\right)\right\|^{2}\left\|Y_{t}\left(n_{T}\right)\right\|^{2}\right. \\
& \left.+\left(\sum_{\tau=n_{T}+1}^{\infty}\left\|\Pi_{\tau}\right\|\left\|Y_{t-\tau}\right\|\right)^{2}\right\} \\
\leq & 3\left\|\tilde{\Pi}\left(n_{T}\right)-\Pi\left(n_{T}\right)\right\|^{2} \frac{1}{T} \sum_{t=1}^{T}\left\|Y_{t}\left(n_{T}\right)\right\|^{2} \\
& +\frac{3}{T} \sum_{t=1}^{T}\left(\sum_{\tau=n_{T}+1}^{\infty}\left\|\Pi_{\tau}\right\|\left\|Y_{t-\tau}\right\|\right)^{2} .
\end{aligned}
$$

Since

$$
\mathrm{E}\left[\frac{1}{T} \sum_{t=1}^{T}\left\|Y_{t}\left(n_{T}\right)\right\|^{2}\right]=\mathrm{E}\left[\frac{1}{T} \sum_{t=1}^{T} \sum_{\tau=1}^{n_{T}}\left\|Y_{t-\tau}\right\|^{2}\right]=n_{T} \mathrm{E}\left(\left\|Y_{t}\right\|^{2}\right)
$$

we have

$$
\frac{1}{T} \sum_{t=1}^{T}\left\|Y_{t}\left(n_{T}\right)\right\|^{2}=O_{p}\left(n_{T}\right)
$$


Further,

$$
\begin{aligned}
\mathrm{E}\left[\frac{1}{T} \sum_{t=1}^{T}\left(\sum_{\tau=n_{T}+1}^{\infty}\left\|\Pi_{\tau}\right\|\left\|Y_{t-\tau}\right\|\right)\right] & =\mathrm{E}\left\|Y_{t}\right\| \frac{1}{T} \sum_{t=1}^{T} \sum_{\tau=n_{T}+1}^{\infty}\left\|\Pi_{\tau}\right\| \\
& \leq \mathrm{E}\left\|Y_{t}\right\| \frac{C}{T} \sum_{t=1}^{T} \frac{\rho^{n_{T}+1}}{1-\rho}=\left(\frac{C \mathrm{E}\left\|Y_{t}\right\| \rho}{1-\rho}\right) \rho^{n_{T}} \\
& =O\left(\rho^{n_{T}}\right),
\end{aligned}
$$

hence

$$
\begin{aligned}
\frac{1}{T} \sum_{t=1}^{T}\left(\sum_{\tau=n_{T}+1}^{\infty}\left\|\Pi_{\tau}\right\|\left\|Y_{t-\tau}\right\|\right) & =O_{p}\left(\rho^{n_{T}}\right) \\
\frac{1}{T} \sum_{t=1}^{T}\left(\sum_{\tau=n_{T}+1}^{\infty}\left\|\Pi_{\tau}\right\|\left\|Y_{t-\tau}\right\|\right)^{2} & \leq T\left[\frac{1}{T} \sum_{t=1}^{T}\left(\sum_{\tau=n_{T}+1}^{\infty}\left\|\Pi_{\tau}\right\|\left\|Y_{t-\tau}\right\|\right)\right]^{2} \\
& =O_{p}\left(T \rho^{2 n_{T}}\right) .
\end{aligned}
$$

and

$$
\begin{gathered}
\frac{1}{T} \sum_{t=1}^{T}\left\|\tilde{u}_{t}\left(n_{T}\right)-u_{t}\right\|^{2} \leq O_{p}\left(\frac{n_{T}}{T}\right) O_{p}\left(n_{T}\right)+O_{p}\left(T \rho^{2 n_{T}}\right)=O_{p}\left(\frac{n_{T}^{2}}{T}\right), \\
\left\|\frac{1}{T} \sum_{t=1}^{T}\left[\tilde{u}_{t}\left(n_{T}\right)-u_{t}\right]\left[\tilde{u}_{t}\left(n_{T}\right)-u_{t}\right]^{\prime}\right\|=O_{p}\left(\frac{n_{T}^{2}}{T}\right) .
\end{gathered}
$$

We can thus conclude that

$$
\begin{aligned}
\left\|\tilde{\Sigma}_{u}\left(n_{T}\right)-\hat{\Sigma}_{T}\right\| & =O_{p}\left(\frac{n_{T}}{T}\right)+O_{p}\left(\frac{n_{T}^{2}}{T}\right)=O_{p}\left(\frac{n_{T}^{2}}{T}\right), \\
\left\|\tilde{\Sigma}_{u}\left(n_{T}\right)-\Sigma_{u}\right\| & =O_{p}\left(\frac{n_{T}^{2}}{T}\right) .
\end{aligned}
$$

Proof of Proposition 4.1 Using (4.2) and (4.8), we see that

$$
\begin{aligned}
\tilde{\Gamma}\left(n_{T}\right)-\Gamma_{T}= & \frac{1}{T} \sum_{t=1}^{T}\left[\tilde{X}_{t}\left(n_{T}\right) \tilde{X}_{t}\left(n_{T}\right)^{\prime}-X_{t} X_{t}^{\prime}\right] \\
= & \frac{1}{T} \sum_{t=1}^{T}\left\{\left[\tilde{X}_{t}\left(n_{T}\right)-X_{t}\right] X_{t}^{\prime}+X_{t}\left[\tilde{X}_{t}\left(n_{T}\right)-X_{t}\right]^{\prime}\right\} \\
& +\frac{1}{T} \sum_{t=1}^{T}\left\{\left[\tilde{X}_{t}\left(n_{T}\right)-X_{t}\right]\left[\tilde{X}_{t}\left(n_{T}\right)-X_{t}\right]^{\prime}\right\}
\end{aligned}
$$


hence, using the triangular and Cauchy-Schwarz inequalities,

$$
\begin{aligned}
\left\|\tilde{\Gamma}\left(n_{T}\right)-\Gamma_{T}\right\| \leq 2( & \left.\frac{1}{T} \sum_{t=1}^{T}\left\|X_{t}\right\|^{2}\right)^{1 / 2}\left(\frac{1}{T} \sum_{t=1}^{T}\left\|\tilde{X}_{t}\left(n_{T}\right)-X_{t}\right\|^{2}\right)^{1 / 2} \\
& +\frac{1}{T} \sum_{t=1}^{T}\left\|\tilde{X}_{t}\left(n_{T}\right)-X_{t}\right\|^{2} \\
=2( & \left.\frac{1}{T}\|X(T)\|^{2}\right)^{1 / 2}\left(\frac{1}{T}\left\|\tilde{X}\left(n_{T}\right)-X(T)\right\|^{2}\right)^{1 / 2} \\
& +\frac{1}{T}\left\|\tilde{X}\left(n_{T}\right)-X(T)\right\|^{2}
\end{aligned}
$$

where

$$
\begin{gathered}
\tilde{X}_{t}\left(n_{T}\right)-X_{t}=\left[\begin{array}{c}
u_{t}-\tilde{u}_{t}\left(n_{T}\right) \\
0 \\
\vdots \\
0 \\
\tilde{u}_{t-1}\left(n_{T}\right)-u_{t-1} \\
\vdots \\
\tilde{u}_{t-\tilde{p}}\left(n_{T}\right)-u_{t-\tilde{p}}
\end{array}\right], \\
\frac{1}{T}\left\|\tilde{X}\left(n_{T}\right)-X(T)\right\|^{2}=\frac{1}{T} \sum_{t=1}^{T}\left\|\tilde{X}_{t}\left(n_{T}\right)-X_{t}\right\|^{2} \\
=\sum_{j=0}^{\bar{p}}\left[\frac{1}{T} \sum_{t=1}^{T}\left\|\tilde{u}_{t-j}\left(n_{T}\right)-u_{t-j}\right\|^{2}\right]=O_{p}\left(\frac{n_{T}^{2}}{T}\right)
\end{gathered}
$$

and, by the stationarity assumption,

$$
\frac{1}{T}\|X(T)\|^{2}=\frac{1}{T} \sum_{t=1}^{T}\left\|X_{t}\right\|^{2}=O_{p}(1) .
$$

It follows from the above orders that

$$
\left\|\tilde{\Gamma}\left(n_{T}\right)-\Gamma_{T}\right\|=O_{p}\left(\frac{n_{T}}{T^{1 / 2}}\right) .
$$

Consequently, we have:

$$
\begin{aligned}
\left\|\tilde{\Upsilon}\left(n_{T}\right)-\Upsilon_{T}\right\| & =\left\|I_{k} \otimes \tilde{\Gamma}\left(n_{T}\right)-I_{k} \otimes \Gamma_{T}\right\| \\
& =\left\|I_{k} \otimes\left(\tilde{\Gamma}\left(n_{T}\right)-\Gamma_{T}\right)\right\| \\
& =k^{1 / 2}\left\|\tilde{\Gamma}\left(n_{T}\right)-\Gamma_{T}\right\|=O_{p}\left(\frac{n_{T}}{T^{1 / 2}}\right)
\end{aligned}
$$




$$
\begin{aligned}
\left\|\tilde{Q}\left(n_{T}\right)^{-1}-Q_{T}^{-1}\right\| & =\left\|R^{\prime}\left[\tilde{\Upsilon}\left(n_{T}\right)-\Upsilon_{T}\right] R\right\| \\
& \leq\|R\|^{2}\left\|\tilde{\Upsilon}\left(n_{T}\right)-\Upsilon_{T}\right\|=O_{p}\left(\frac{n_{T}}{T^{1 / 2}}\right)
\end{aligned}
$$

Further, since

$$
\left\|\tilde{Q}\left(n_{T}\right)^{-1}-Q^{-1}\right\| \leq\left\|\tilde{Q}\left(n_{T}\right)^{-1}-Q_{T}^{-1}\right\|+\left\|Q_{T}^{-1}-Q^{-1}\right\|
$$

and

$$
\begin{aligned}
\left\|Q_{T}^{-1}-Q^{-1}\right\| & =\left\|R^{\prime}\left(\Upsilon_{T}-\Upsilon\right) R\right\| \leq\|R\|^{2}\left\|\Upsilon_{T}-\Upsilon\right\| \\
& \leq\|R\|^{2}\left\|I_{k} \otimes\left(\Gamma_{T}-\Gamma\right)\right\|=k^{1 / 2}\|R\|^{2}\left\|\Gamma_{T}-\Gamma\right\| \\
& =k^{1 / 2}\|R\|^{2}\left\|\frac{1}{T} \sum_{t=1}^{T} X_{t} X_{t}^{\prime}-\mathrm{E}\left(X_{t} X_{t}^{\prime}\right)\right\|=O_{p}\left(\frac{1}{T^{1 / 2}}\right)
\end{aligned}
$$

we have:

$$
\left\|\tilde{Q}\left(n_{T}\right)^{-1}-Q^{-1}\right\|=O_{p}\left(\frac{n_{T}}{T^{1 / 2}}\right) .
$$

Finally, using the triangular inequality, we get:

$$
\begin{aligned}
& \left\|\tilde{Q}\left(n_{T}\right)\right\| \leq\left\|\tilde{Q}\left(n_{T}\right)-Q\right\|+\|Q\|, \\
\left\|\tilde{Q}\left(n_{T}\right)-Q\right\| & =\left\|\tilde{Q}\left(n_{T}\right)\left[\tilde{Q}\left(n_{T}\right)^{-1}-Q^{-1}\right] Q\right\| \\
& \leq\left\|\tilde{Q}\left(n_{T}\right)\right\|\left\|\tilde{Q}\left(n_{T}\right)^{-1}-Q^{-1}\right\|\|Q\| \\
& \leq\left[\left\|\tilde{Q}\left(n_{T}\right)-Q\right\|+\|Q\|\right]\left\|\tilde{Q}\left(n_{T}\right)^{-1}-Q^{-1}\right\|\|Q\|,
\end{aligned}
$$

hence, for $\left\|\tilde{Q}\left(n_{T}\right)^{-1}-Q^{-1}\right\|\|Q\|<1$ (an event whose probability converges to 1 as $T \rightarrow \infty$ )

$$
\left\|\tilde{Q}\left(n_{T}\right)-Q\right\| \leq \frac{\|Q\|^{2}\left\|\tilde{Q}\left(n_{T}\right)^{-1}-Q^{-1}\right\|}{1-\left\|\tilde{Q}\left(n_{T}\right)^{-1}-Q^{-1}\right\|\|Q\|}=O_{p}\left(\frac{n_{T}}{T^{1 / 2}}\right) .
$$

ProOF OF THEOREM 4.1 Recall that $\tilde{\eta}-\eta=\tilde{Q}\left(n_{T}\right) \tilde{\Omega}\left(n_{T}\right)$. Then, we have

$$
\begin{aligned}
\|\tilde{\eta}-\eta\| & \leq\|Q\|_{1}\left\|\Omega_{T}\right\|+\left\|\tilde{Q}\left(n_{T}\right)-Q\right\|_{1}\left\|\Omega_{T}\right\|+\left\|\tilde{Q}\left(n_{T}\right)\right\|_{1}\left\|\tilde{\Omega}\left(n_{T}\right)-\Omega_{T}\right\| \\
& \leq\|Q\|\left\|\Omega_{T}\right\|+\left\|\tilde{Q}\left(n_{T}\right)-Q\right\|\left\|\Omega_{T}\right\|+\left\|\tilde{Q}\left(n_{T}\right)\right\|\left\|\tilde{\Omega}\left(n_{T}\right)-\Omega_{T}\right\| .
\end{aligned}
$$

\section{By Proposition 4.1,}

$$
\left\|\tilde{Q}\left(n_{T}\right)-Q\right\|=O_{p}\left(\frac{n_{T}}{T^{1 / 2}}\right), \quad\left\|\tilde{Q}\left(n_{T}\right)\right\|=O_{p}(1) .
$$


Now

$$
\Omega_{T}=\frac{1}{T} \sum_{t=1}^{T} R^{\prime}\left[I_{k} \otimes X_{t}\right] u_{t}=R^{\prime} \operatorname{vec}\left[\frac{1}{T} \sum_{t=1}^{T} X_{t} u_{t}^{\prime}\right]
$$

so that

$$
\mathrm{E}\left\|\Omega_{T}\right\|^{2} \leq\|R\|^{2} \mathrm{E}\left\|W_{T}\right\|^{2}
$$

where

$$
W_{T}=\frac{1}{T} \sum_{t=1}^{T} X_{t} u_{t}^{\prime}
$$

Then, using the fact that $u_{t}$ is independent of $X_{t}, u_{t-1}, \ldots, u_{1}$,

$$
\begin{aligned}
\mathrm{E}\left\|W_{T}\right\|^{2} & =\mathrm{E}\left[\operatorname{tr}\left(W_{T} W_{T}^{\prime}\right)\right] \\
& =\frac{1}{T^{2}}\left\{\sum_{t=1}^{T} \mathrm{E}\left(\operatorname{tr}\left[X_{t} u_{t}^{\prime} u_{t} X_{t}^{\prime}\right]\right)+2 \sum_{t=1}^{T-1} \sum_{l=1}^{T-l}\left\{\mathrm{E}\left(\operatorname{tr}\left[X_{t} u_{t}^{\prime} u_{t+l} X_{t+l}^{\prime}\right]\right)\right\}\right. \\
& =\frac{1}{T^{2}}\left\{\sum_{t=1}^{T} \mathrm{E}\left(\operatorname{tr}\left[u_{t}^{\prime} u_{t} X_{t}^{\prime} X_{t}\right]\right)+2 \sum_{t=1}^{T-1} \sum_{l=1}^{T-l}\left\{\mathrm{E}\left(\operatorname{tr}\left[u_{t+l} X_{t+l}^{\prime} X_{t} u_{t}^{\prime}\right]\right)\right\}\right. \\
& =\frac{1}{T^{2}}\left\{\sum_{t=1}^{T} \operatorname{tr}\left[\mathrm{E}\left(u_{t}^{\prime} u_{t}\right) \mathrm{E}\left(X_{t}^{\prime} X_{t}\right)\right]+2 \sum_{t=1}^{T-1} \sum_{l=1}^{T-l}\left\{\mathrm{E}\left(\operatorname{tr}\left[\mathrm{E}\left(u_{t+l}\right) \mathrm{E}\left(X_{t+l}^{\prime} X_{t} u_{t}^{\prime}\right)\right]\right)\right\}\right. \\
& =\frac{1}{T^{2}}\left\{\sum_{t=1}^{T} \operatorname{tr}\left[\mathrm{E}\left(u_{t} u_{t}^{\prime}\right) \mathrm{E}\left(X_{t}^{\prime} X_{t}\right)\right]\right\}=\frac{1}{T} \operatorname{tr}\left(\Sigma_{u}\right) \operatorname{tr}(\Gamma)
\end{aligned}
$$

hence

$$
\left\|W_{T}\right\|=O_{p}\left(T^{-1 / 2}\right), \quad\left\|\Omega_{T}\right\|=O_{p}\left(T^{-1 / 2}\right) .
$$

Now, consider the term $\left\|\tilde{\Omega}\left(n_{T}\right)-\Omega_{T}\right\|$. We have:

$$
\begin{aligned}
\tilde{\Omega}\left(n_{T}\right)-\Omega_{T} & =\frac{1}{T} R^{\prime} \sum_{t=1}^{T}\left\{\left[I_{k} \otimes \tilde{X}_{t}\left(n_{T}\right)\right] e_{t}\left(n_{T}\right)-\left[I_{k} \otimes X_{t}\right] u_{t}\right\} \\
& =R^{\prime} \operatorname{vec}\left[\frac{1}{T} \sum_{t=1}^{T}\left\{\tilde{X}_{t}\left(n_{T}\right) e_{t}\left(n_{T}\right)^{\prime}-X_{t} u_{t}^{\prime}\right\}\right] \\
& =R^{\prime} \operatorname{vec}\left\{\tilde{\Omega}_{1}\left(n_{T}\right)+\tilde{\Omega}_{2}\left(n_{T}\right)\right\}
\end{aligned}
$$

where

$$
\tilde{\Omega}_{1}\left(n_{T}\right)=\frac{1}{T} \sum_{t=1}^{T} X_{t}\left[e_{t}\left(n_{T}\right)-u_{t}\right]^{\prime}
$$




$$
\begin{aligned}
\tilde{\Omega}_{2}\left(n_{T}\right) & =\frac{1}{T} \sum_{t=1}^{T}\left[\tilde{X}_{t}\left(n_{T}\right)-X_{t}\right] e_{t}\left(n_{T}\right)^{\prime} \\
e_{t}\left(n_{T}\right) & =\tilde{u}_{t}\left(n_{T}\right)+\sum_{j=0}^{\bar{p}} \Theta_{j}\left[u_{t-j}-\tilde{u}_{t-j}\left(n_{T}\right)\right] .
\end{aligned}
$$

We can also write

$$
e_{t}\left(n_{T}\right)-u_{t}=\sum_{j=0}^{\bar{p}} \bar{\Theta}_{j}\left[\tilde{u}_{t-j}\left(n_{T}\right)-u_{t-j}\right]
$$

where $\bar{\Theta}_{0}=I_{k}-\Theta_{0}$ and $\bar{\Theta}_{j}=-\Theta_{j}, j=1,2, \ldots, \bar{p}$, and

$$
\begin{aligned}
\tilde{u}_{t}\left(n_{T}\right)-u_{t} & =\left[\Pi\left(n_{T}\right)-\tilde{\Pi}\left(n_{T}\right)\right] Y_{t}\left(n_{T}\right)+\sum_{\tau=n_{T}+1}^{\infty} \Pi_{\tau} Y_{t-\tau} \\
& =\sum_{\tau=1}^{n_{T}}\left[\Pi_{\tau}-\tilde{\Pi}_{\tau}\left(n_{T}\right)\right] Y_{t-\tau}+\sum_{\tau=n_{T}+1}^{\infty} \Pi_{\tau} Y_{t-\tau},
\end{aligned}
$$

hence

$$
\begin{aligned}
\tilde{\Omega}_{1}\left(n_{T}\right) & =\frac{1}{T} \sum_{t=1}^{T} X_{t}\left[e_{t}\left(n_{T}\right)-u_{t}\right]^{\prime} \\
& =\sum_{j=0}^{\bar{p}}\left\{\frac{1}{T} \sum_{t=1}^{T}\left\{\sum_{\tau=1}^{n_{T}} X_{t} Y_{t-j-\tau}^{\prime}\left[\Pi_{\tau}-\tilde{\Pi}_{\tau}\left(n_{T}\right)\right]^{\prime}+\sum_{\tau=n_{T}+1}^{\infty} X_{t} Y_{t-j-\tau}^{\prime} \Pi_{\tau}^{\prime}\right\}\right\} \bar{\Theta}_{j}^{\prime} \\
& =\sum_{j=0}^{\bar{p}}\left\{\sum_{\tau=1}^{n_{T}}\left\{\frac{1}{T} \sum_{t=1}^{T} X_{t} Y_{t-j-\tau}^{\prime}\right\}\left[\Pi_{\tau}-\tilde{\Pi}_{\tau}\left(n_{T}\right)\right]^{\prime}+\frac{1}{T} \sum_{t=1}^{T} \sum_{\tau=n_{T}+1}^{\infty} X_{t} Y_{t-j-\tau}^{\prime} \Pi_{\tau}^{\prime}\right\} \bar{\Theta}_{j}^{\prime} \\
& =\tilde{\Omega}_{11}\left(n_{T}\right)+\tilde{\Omega}_{12}\left(n_{T}\right)
\end{aligned}
$$

where

$$
\begin{aligned}
\tilde{\Omega}_{11}\left(n_{T}\right) & =\sum_{j=0}^{\bar{p}}\left\{\sum_{\tau=1}^{n_{T}} \tilde{\Gamma}_{j+\tau}\left(n_{T}\right)\left[\Pi_{\tau}-\tilde{\Pi}_{\tau}\left(n_{T}\right)\right]^{\prime}\right\} \bar{\Theta}_{j}^{\prime}, \\
\tilde{\Gamma}_{j+\tau}\left(n_{T}\right) & =\frac{1}{T} \sum_{t=1}^{T} X_{t} Y_{t-j-\tau}^{\prime}, \\
\tilde{\Omega}_{12}\left(n_{T}\right) & =\sum_{j=0}^{\bar{p}}\left\{\frac{1}{T} \sum_{t=1}^{T} \sum_{\tau=n_{T}+1}^{\infty} X_{t} Y_{t-j-\tau}^{\prime} \Pi_{\tau}^{\prime}\right\} \bar{\Theta}_{j}^{\prime} .
\end{aligned}
$$


Now, using the linearity and the VARMA structure of $Y_{t}$, it is easy to see that

$$
\mathrm{E}\left\|\tilde{\Gamma}_{j+\tau}\left(n_{T}\right)\right\|^{2} \leq \frac{1}{T} C_{1} \rho_{1}^{j+\tau}
$$

for some constants $C_{1}>0$ and $0<\rho_{1}<1$, hence

$$
\mathrm{E}\left[\sum_{\tau=1}^{n_{T}}\left\|\tilde{\Gamma}_{j+\tau}\left(n_{T}\right)\right\|^{2}\right] \leq \frac{1}{T} C_{1} \sum_{\tau=1}^{n_{T}} \rho_{1}^{j+\tau} \leq \frac{1}{T} \frac{C_{1}}{1-\rho_{1}}=O_{p}\left(\frac{1}{T}\right) .
$$

Thus

$$
\begin{aligned}
\left\|\tilde{\Omega}_{11}\left(n_{T}\right)\right\| & \leq \sum_{j=0}^{\bar{p}}\left\{\sum_{\tau=1}^{n_{T}}\left\|\tilde{\Gamma}_{j+\tau}\left(n_{T}\right)\right\|\left\|\Pi_{\tau}-\tilde{\Pi}_{\tau}\left(n_{T}\right)\right\|\right\}\left\|\bar{\Theta}_{j}\right\| \\
& \leq \sum_{j=0}^{\bar{p}}\left\{\left[\sum_{\tau=1}^{n_{T}}\left\|\tilde{\Gamma}_{j+\tau}\left(n_{T}\right)\right\|^{2}\right]^{1 / 2}\left[\sum_{\tau=1}^{n_{T}}\left\|\Pi_{\tau}-\tilde{\Pi}_{\tau}\left(n_{T}\right)\right\|^{2}\right]^{1 / 2}\right\}\left\|\bar{\Theta}_{j}\right\| \\
& \leq \sum_{j=0}^{\bar{p}}\left\{\left[\sum_{\tau=1}^{n_{T}}\left\|\tilde{\Gamma}_{j+\tau}\left(n_{T}\right)\right\|^{2}\right]^{1 / 2}\left\|\tilde{\Pi}\left(n_{T}\right)-\Pi\left(n_{T}\right)\right\|\right\}\left\|\bar{\Theta}_{j}\right\| \\
& =O_{p}\left(\frac{n_{T}^{1 / 2}}{T}\right)
\end{aligned}
$$

while

$$
\begin{aligned}
\mathrm{E}\left\|\tilde{\Omega}_{12}\left(n_{T}\right)\right\| & \leq \sum_{j=0}^{\bar{p}}\left\{\mathrm{E}\left[\frac{1}{T} \sum_{t=1}^{T} \sum_{\tau=n_{T}+1}^{\infty}\left\|X_{t}\right\|\left\|Y_{t-j-\tau}\right\|\left\|\Pi_{\tau}\right\|\right]\right\}\left\|\bar{\Theta}_{j}\right\| \\
& \leq \sum_{j=0}^{\bar{p}}\left\{\frac{1}{T} \sum_{t=1}^{T} \sum_{\tau=n_{T}+1}^{\infty}\left\|\Pi_{\tau}\right\| \mathrm{E}\left[\left\|X_{t}\right\|\left\|Y_{t-j-\tau}\right\|\right]\right\}\left\|\bar{\Theta}_{j}\right\| \\
& \leq \sum_{j=0}^{\bar{p}}\left\{\left[\mathrm{E}\left(\left\|X_{t}\right\|^{2}\right) \mathrm{E}\left(\left\|Y_{t}\right\|^{2}\right)\right]^{1 / 2} \frac{1}{T} \sum_{t=1}^{T} \sum_{\tau=n_{T}+1}^{\infty}\left\|\Pi_{\tau}\right\|\right\}\left\|\bar{\Theta}_{j}\right\| \\
& =O_{p}\left(\rho^{n_{T}}\right),
\end{aligned}
$$

hence $\left\|\tilde{\Omega}_{12}\left(n_{T}\right)\right\|=O_{p}\left(\rho^{n_{T}}\right)$ and

$$
\left\|\tilde{\Omega}_{1}\left(n_{T}\right)\right\| \leq\left\|\tilde{\Omega}_{11}\left(n_{T}\right)\right\|+\left\|\tilde{\Omega}_{12}\left(n_{T}\right)\right\|=O_{p}\left(\frac{n_{T}^{1 / 2}}{T}\right) .
$$

Now, using (A.55), $\tilde{\Omega}_{2}\left(n_{T}\right)$ can be decomposed as:

$$
\tilde{\Omega}_{2}\left(n_{T}\right)=\tilde{\Omega}_{21}\left(n_{T}\right)+\tilde{\Omega}_{22}\left(n_{T}\right)
$$


where

$$
\begin{aligned}
& \tilde{\Omega}_{21}\left(n_{T}\right)=\frac{1}{T} \sum_{t=1}^{T}\left[\tilde{X}_{t}\left(n_{T}\right)-X_{t}\right] u_{t}^{\prime}, \\
& \tilde{\Omega}_{22}\left(n_{T}\right)=\sum_{j=0}^{\bar{p}}\left\{\frac{1}{T} \sum_{t=1}^{T}\left[\tilde{X}_{t}\left(n_{T}\right)-X_{t}\right]\left[\tilde{u}_{t-j}\left(n_{T}\right)-u_{t-j}\right]^{\prime}\right\} \bar{\Theta}_{j}^{\prime} .
\end{aligned}
$$

Now, in view of (A.32), consider the variables:

$$
\begin{aligned}
C_{i}\left(n_{T}\right) & =\frac{1}{T} \sum_{t=1}^{T}\left[\tilde{u}_{t-i}\left(n_{T}\right)-u_{t-i}\right] u_{t}^{\prime} \\
& =\sum_{\tau=1}^{n_{T}}\left[\Pi_{\tau}-\tilde{\Pi}_{\tau}\left(n_{T}\right)\right]\left(\frac{1}{T} \sum_{t=1}^{T} Y_{t-i-\tau} u_{t}^{\prime}\right)+\frac{1}{T} \sum_{t=1}^{T} \sum_{\tau=n_{T}+1}^{\infty} \Pi_{\tau} Y_{t-i-\tau} u_{t}^{\prime}, \\
C_{i j}\left(n_{T}\right) & =\frac{1}{T} \sum_{t=1}^{T}\left[\tilde{u}_{t-i}\left(n_{T}\right)-u_{t-i}\right]\left[\tilde{u}_{t-j}\left(n_{T}\right)-u_{t-j}\right]^{\prime},
\end{aligned}
$$

for $i=0,1, \ldots, \bar{p}$. We have:

$$
\begin{aligned}
\mathrm{E}\left\|\frac{1}{T} \sum_{t=1}^{T} Y_{t-i-\tau} u_{t}^{\prime}\right\|^{2} & =\frac{1}{T^{2}} \sum_{t=1}^{T} \operatorname{Etr}\left[Y_{t-i-\tau} u_{t}^{\prime} u_{t} Y_{t-i-\tau}^{\prime}\right]=\frac{1}{T^{2}} \sum_{t=1}^{T} \operatorname{tr}\left[\mathrm{E}\left(u_{t}^{\prime} u_{t}\right) \mathrm{E}\left(Y_{t-i-\tau}^{\prime} Y_{t-i-\tau}\right)\right] \\
& =\frac{1}{T} \operatorname{tr}\left(\Sigma_{u}\right) \operatorname{tr}[\Gamma(0)]
\end{aligned}
$$

where $\Gamma(0)=\mathrm{E}\left(Y_{t} Y_{t}^{\prime}\right)$, hence

$$
\begin{aligned}
\sum_{\tau=1}^{n_{T}} \mathrm{E}\left\|\frac{1}{T} \sum_{t=1}^{T} Y_{t-i-\tau} u_{t}^{\prime}\right\|^{2} & =\frac{n_{T}}{T} \operatorname{tr}\left(\Sigma_{u}\right) \operatorname{tr}[\Gamma(0)], \\
\sum_{\tau=1}^{n_{T}}\left\|\frac{1}{T} \sum_{t=1}^{T} Y_{t-i-\tau} u_{t}^{\prime}\right\|^{2} & =O_{p}\left(\frac{n_{T}}{T}\right),
\end{aligned}
$$

and

$$
\begin{aligned}
\left\|C_{i}\left(n_{T}\right)\right\| \leq & \sum_{\tau=1}^{n_{T}}\left\|\Pi_{\tau}-\tilde{\Pi}_{\tau}\left(n_{T}\right)\right\|\left\|\frac{1}{T} \sum_{t=1}^{T} Y_{t-i-\tau} u_{t}^{\prime}\right\| \\
& +\frac{1}{T} \sum_{t=1}^{T} \sum_{\tau=n_{T}+1}^{\infty}\left\|\Pi_{\tau}\right\|\left\|Y_{t-i-\tau}\right\|\left\|u_{t}\right\|
\end{aligned}
$$




$$
\begin{aligned}
\leq & {\left[\sum_{\tau=1}^{n_{T}}\left\|\Pi_{\tau}-\tilde{\Pi}_{\tau}\left(n_{T}\right)\right\|^{2}\right]^{1 / 2}\left[\sum_{\tau=1}^{n_{T}}\left\|\frac{1}{T} \sum_{t=1}^{T} Y_{t-i-\tau} u_{t}^{\prime}\right\|^{2}\right]^{1 / 2} } \\
& +\frac{1}{T} \sum_{t=1}^{T} \sum_{\tau=n_{T}+1}^{\infty}\left\|\Pi_{\tau}\right\|\left\|Y_{t-i-\tau}\right\|\left\|u_{t}\right\| \\
= & \left\|\tilde{\Pi}\left(n_{T}\right)-\Pi\left(n_{T}\right)\right\|\left[\sum_{\tau=1}^{n_{T}}\left\|\frac{1}{T} \sum_{t=1}^{T} Y_{t-i-\tau} u_{t}^{\prime}\right\|^{2}\right]^{1 / 2} \\
& \quad+\frac{1}{T} \sum_{t=1}^{T} \sum_{\tau=n_{T}+1}^{\infty}\left\|\Pi_{\tau}\right\|\left\|Y_{t-i-\tau}\right\|\left\|u_{t}\right\| \\
= & O_{p}\left(\frac{n_{T}}{T}\right) \cdot
\end{aligned}
$$

Further,

$$
\begin{aligned}
\left\|C_{i j}\left(n_{T}\right)\right\| & \leq \frac{1}{T} \sum_{t=1}^{T}\left\|\left[\tilde{u}_{t-i}\left(n_{T}\right)-u_{t-i}\right]\right\|\left\|\left[\tilde{u}_{t-j}\left(n_{T}\right)-u_{t-j}\right]^{\prime}\right\| \\
& \leq\left[\frac{1}{T} \sum_{t=1}^{T}\left\|\tilde{u}_{t-i}\left(n_{T}\right)-u_{t-i}\right\|^{2}\right]^{1 / 2}\left[\frac{1}{T} \sum_{t=1}^{T}\left\|\tilde{u}_{t-j}\left(n_{T}\right)-u_{t-j}\right\|^{2}\right]^{1 / 2} \\
& =O_{p}\left(\frac{n_{T}^{2}}{T}\right)
\end{aligned}
$$

Thus

$$
\left\|\tilde{\Omega}_{21}\left(n_{T}\right)\right\|=O_{p}\left(n_{T} / T\right), \quad\left\|\tilde{\Omega}_{22}\left(n_{T}\right)\right\|=O_{p}\left(\frac{n_{T}^{2}}{T}\right)
$$

hence

$$
\begin{aligned}
\left\|\tilde{\Omega}_{2}\left(n_{T}\right)\right\| \leq & \left\|\tilde{\Omega}_{21}\left(n_{T}\right)\right\|+\left\|\tilde{\Omega}_{22}\left(n_{T}\right)\right\|=O_{p}\left(\frac{n_{T}^{2}}{T}\right), \\
\left\|\tilde{\Omega}\left(n_{T}\right)-\Omega_{T}\right\| & \leq\|R\|\left(\left\|\tilde{\Omega}_{1}\left(n_{T}\right)\right\|+\left\|\tilde{\Omega}_{2}\left(n_{T}\right)\right\|\right) \\
& =O_{p}\left(\frac{n_{T}^{1 / 2}}{T}\right)+O_{p}\left(\frac{n_{T}^{2}}{T}\right)=O_{p}\left(\frac{n_{T}^{2}}{T}\right) .
\end{aligned}
$$

Consequently,

$$
\begin{aligned}
\|\tilde{\eta}-\eta\| & \leq O_{p}\left(\frac{1}{T^{1 / 2}}\right)+O_{p}\left(\frac{n_{T}}{T}\right)+O_{p}\left(\frac{n_{T}^{2}}{T}\right) \\
& =O_{p}\left(\frac{1}{T^{1 / 2}}\right)+O_{p}\left(\frac{n_{T}^{2}}{T}\right)=o_{p}(1) .
\end{aligned}
$$


If furthermore $n_{T}^{4} / T \longrightarrow 0$ as $T \rightarrow \infty$, the latter reduces to

$$
\|\tilde{\eta}-\eta\|=O_{p}\left(\frac{1}{T^{1 / 2}}\right) .
$$

ProOF OF Proposition 4.2 We have:

$$
\begin{aligned}
\left\|\tilde{S}\left(n_{T}\right)-S_{T}\right\| & =T^{1 / 2}\left\|\tilde{Q}\left(n_{T}\right) \tilde{\Omega}\left(n_{T}\right)-Q \Omega_{T}\right\| \\
& \leq T^{1 / 2}\left\|\tilde{Q}\left(n_{T}\right)\right\|\left\|\tilde{\Omega}\left(n_{T}\right)-\Omega_{T}\right\|+T^{1 / 2}\left\|\tilde{Q}\left(n_{T}\right)-Q\right\|\left\|\Omega_{T}\right\| .
\end{aligned}
$$

By Proposition 4.1 and Theorem 4.1, the following orders hold:

$$
\begin{aligned}
\left\|\tilde{Q}\left(n_{T}\right)-Q\right\| & =O_{p}\left(\frac{n_{T}}{T^{1 / 2}}\right), \quad\left\|\tilde{Q}\left(n_{T}\right)\right\|=O_{p}(1), \\
\left\|\tilde{\Omega}\left(n_{T}\right)-\Omega_{T}\right\| & =O_{p}\left(\frac{n_{T}^{2}}{T}\right), \quad\left\|\Omega_{T}\right\|=O_{p}\left(\frac{1}{T^{1 / 2}}\right) .
\end{aligned}
$$

Therefore,

$$
\left\|\tilde{S}\left(n_{T}\right)-S_{T}\right\|=O_{p}\left(\frac{n_{T}^{2}}{T^{1 / 2}}\right) .
$$

Proof of THEOREM 4.3 By the standard central limit theorem for stationary processes [see Anderson (1971, section 7.7), Lewis and Reinsel (1985, section 2)] and under the assumption of independence between $u_{t}$ and $X_{t}$, we have:

$$
T^{1 / 2} \Omega_{T}=\frac{1}{T^{1 / 2}} \sum_{t=1}^{T} R^{\prime}\left(I_{k} \otimes X_{t}\right) u_{t}=\frac{1}{T^{1 / 2}} \sum_{t=1}^{T} R^{\prime}\left(u_{t} \otimes X_{t}\right) \underset{T \rightarrow \infty}{\longrightarrow} \mathrm{N}\left[0, \Sigma_{X u}\right]
$$

where

$$
\begin{aligned}
\Sigma_{X u} & =\mathrm{E}\left\{R^{\prime}\left(u_{t} \otimes X_{t}\right)\left(u_{t} \otimes X_{t}\right)^{\prime} R\right\}=\mathrm{E}\left\{R^{\prime}\left[u_{t} u_{t}^{\prime} \otimes X_{t} X_{t}^{\prime}\right] R\right\} \\
& =R^{\prime}\left[\mathrm{E}\left(u_{t} u_{t}^{\prime}\right) \otimes \mathrm{E}\left(X_{t} X_{t}^{\prime}\right)\right] R=R^{\prime}\left[\Sigma_{u} \otimes \Gamma\right] R .
\end{aligned}
$$

Then

$$
S_{T}=T^{1 / 2} Q \Omega_{T} \underset{T \rightarrow \infty}{\longrightarrow} \mathrm{N}\left[0, \Sigma_{\eta}\right]
$$

where

$$
\Sigma_{\eta}=Q \Sigma_{X u} Q^{\prime} .
$$


Finally, by Proposition 4.2, we can conclude that

$$
\sqrt{T}(\tilde{\eta}-\eta)=\tilde{S}\left(n_{T}\right) \underset{T \rightarrow \infty}{\longrightarrow} \mathrm{N}\left[0, \Sigma_{\eta}\right] .
$$




\section{References}

Akaike, H. (1976), Canonical correlation analysis of time series and the use of an information criterion, in R. K. Mehra and D. G. Lainiotis, eds, 'System Identification: Advances in Case Studies', Academic Press, New York, pp. 27-96.

Anderson, T. W. (1971), The Statistical Analysis of Time Series, John Wiley \& Sons, New York.

Bartel, H. and Lütkepohl, H. (1998), 'Estimating the Kronecker indices of cointegrated echelonform VARMA models', Econometrics Journal 1, C76-C99.

Boudjellaba, H., Dufour, J.-M. and Roy, R. (1992), 'Testing causality between two vectors in multivariate ARMA models', Journal of the American Statistical Association 87(420), 1082-1090.

Boudjellaba, H., Dufour, J.-M. and Roy, R. (1994), 'Simplified conditions for non-causality between two vectors in multivariate ARMA models', Journal of Econometrics 63, 271-287.

Cooper, D. M. and Wood, E. F. (1982), 'Identifying multivariate time series models', Journal of Time Series Analysis 3(3), 153-164.

Deistler, M. and Hannan, E. J. (1981), 'Some properties of the parameterization of ARMA systems with unknown order', Journal of Multivariate Analysis 11, 474-484.

Durbin, J. (1960), 'The fitting of time series models', Revue de l'Institut International de Statistique 28, 233-244.

Flores de Frutos, R. and Serrano, G. R. (2002), 'A generalized least squares estimation method for VARMA models’, Statistics 36(4), 303-316.

Galbraith, J. W. and Zinde-Walsh, V. (1994), 'A simple, noniterative estimator for moving average models', Biometrika 81(1), 143-155.

Galbraith, J. W. and Zinde-Walsh, V. (1997), 'On some simple, autoregression-based estimation and identification techniques for ARMA models', Biometrika 84(3), 685-696.

Hamilton, J. D. (1994), Time Series Analysis, Princeton University Press, Princeton, New Jersey.

Hannan, E. J. (1969), 'The identification of vector mixed autoregressive- moving average systems', Biometrika 57, 223-225.

Hannan, E. J. (1970), Multiple Time Series, John Wiley \& Sons, New York.

Hannan, E. J. (1976a), 'The asymptotic distribution of serial covariances', The Annals of Statistics 4(2), 396-399.

Hannan, E. J. (1976b), 'The identification and parameterization of ARMAX and state space forms', Econometrica 44(4), 713-723. 
Hannan, E. J. (1979), The statistical theory of linear systems, in P. R. Krishnaiah, ed., 'Developments in Statistics', Vol. 2, Academic Press, New York, pp. 83-121.

Hannan, E. J. and Deistler, M. (1988), The Statistical Theory of Linear Systems, John Wiley \& Sons, New York.

Hannan, E. J. and Kavalieris, L. (1984a), ‘A method for autoregressive-moving average estimation', Biometrika 71(2), 273-280.

Hannan, E. J. and Kavalieris, L. (1984b), 'Multivariate linear time series models', Advances in Applied Probability 16, 492-561.

Hannan, E. J. and Kavalieris, L. (1986), 'Regression, autoregression models', Journal of Time Series Analysis 7(1), 27-49.

Hannan, E. J., Kavalieris, L. and Mackisack, M. (1986), 'Recursive estimation of linear systems', Biometrika 73(1), 119-133.

Hannan, E. J. and Rissanen, J. (1982), 'Recursive estimation of mixed autoregressive-movingaverage order', Biometrika 69(1), 81-94. Errata 70 (1983), 303.

Hillmer, S. C. and Tiao, G. C. (1979), 'Likelihood function of stationary multiple autoregressive moving average models', Journal of the American Statistical Association 74(367), 652-660.

Horn, R. G. and Johnson, C. A. (1985), Matrix Analysis, Cambridge University Press, Cambridge, U.K.

Huang, D. and Guo, L. (1990), 'Estimation of nonstationary ARMAX models based on the HannanRissanen method', The Annals of Statistics 18(4), 1729-1756.

Koreisha, S. G. and Pukkila, T. M. (1989), 'Fast linear estimation methods for vector autoregressive moving-average models', Journal of Time Series Analysis 10(4), 325-339.

Koreisha, S. G. and Pukkila, T. M. (1990a), 'A generalized least-squares approach for estimation of autoregressive-moving-average models', Journal of Time Series Analysis 11(2), 139-151.

Koreisha, S. G. and Pukkila, T. M. (1990b), 'Linear methods for estimating ARMA and regression models with serial correlation', Communications in Statistics, Part B-Simulation and Computation 19(1), 71-102.

Koreisha, S. G. and Pukkila, T. M. (1995), 'A comparison between different order-determination criteria for identification of ARIMA models', Journal of Business and Economic Statistics 13(1), 127-131.

Lewis, R. and Reinsel, G. C. (1985), 'Prediction of multivariate time series by autoregressive model fitting', Journal of Multivariate Analysis 16, 393-411.

Lütkepohl, H. (1987), Forecasting Aggregated Vector ARMA Processes, Springer-Verlag, Berlin. 
Lütkepohl, H. (1991), Introduction to Multiple Time Series Analysis, Springer-Verlag, Berlin.

Lütkepohl, H. (2001), Vector autoregressions, in B. Baltagi, ed., 'Companion to Theoretical Econometrics', Blackwell Companions to Contemporary Economics, Basil Blackwell, Oxford, U.K., chapter 32, pp. 678-699.

Lütkepohl, H. and Claessen, H. (1997), 'Analysis of cointegrated VARMA processes', Journal of Econometrics 80(2), 223-39.

Lütkepohl, H. and Poskitt, D. S. (1996), 'Specification of echelon-form VARMA models', Journal of Business and Economic Statistics 14(1), 69-79.

Mauricio, J. A. (2002), 'An algorithm for the exact likelihood of a stationary vector autoregressivemoving average model', Journal of Time Series Analysis 23(4), 473-486.

Mélard, G., Roy, R. and Saidi, A. (2002), Exact maximum likelihood estimation of structured or unit roots multivariate time series models, Technical report, Institut de Statistique, Université Libre de Bruxelles, and Départment de mathématiques et statistique, Université de Montréal.

Nsiri, S. and Roy, R. (1992), 'On the identification of ARMA echelon-form models', Canadian Journal of Statistics 20(4), 369-386.

Nsiri, S. and Roy, R. (1996), 'Identification of refined ARMA echelon form models for multivariate time series', Journal of Multivariate Analysis 56, 207-231.

Paparoditis, E. (1996), 'Bootstrapping autoregressive and moving average parameter estimates of infinite order vector autoregressive processes', Journal of Multivariate Analysis 57, 277-296.

Poskitt, D. S. (1987), 'A modified Hannan-Rissanen strategy for mixed autoregressive-moving average oder determination', Biometrika 74(4), 781-790.

Poskitt, D. S. (1992), 'Identification of echelon canonical forms for vector linear processes using least squares', The Annals of Statistics 20(1), 195-215.

Poskitt, D. S. and Lütkepohl, H. (1995), Consistent specification of cointegrated autoregressive moving-average systems, Technical Report 54, Institut für Statistik und Ökonometrie, Humboldt-Universität zu Berlin.

Pukkila, T., Koreisha, S. and Kallinen, A. (1990), 'The identification of ARMA models', Biometrika 77(3), 537-548.

Reinsel, G. C. (1997), Elements of Multivariate Time Series Analysis, second edn, Springer-Verlag, New York.

Shea, B. L. (1989), 'The exact likelihood of a vector autoregressive moving average model', Journal of the Royal Statistical Society Series C, Applied Statistics 38(1), 161-184. 
Tiao, G. C. and Box, G. E. P. (1981), 'Modeling multiple time series with applications', Journal of the American Statistical Association 76(376), 802-816.

Tiao, G. C. and Tsay, R. S. (1985), A canonical correlation approach to modeling multivariate time series, in 'Proceedings of the Business and Economic Statistics Section of the American Statistical Association', Washington, D.C., pp. 112-120.

Tiao, G. C. and Tsay, R. S. (1989), 'Model specification in multivariate time series', Journal of the Royal Statistical Society, Series B 51(2), 157-213.

Tsay, R. S. (1989a), 'Identifying multivariate time series models', Journal of Time Series Analysis 10(4), 357-372.

Tsay, R. S. (1989b), 'Parsimonious parameterization of vector autoregressive moving average models', Journal of Business and Economic Statistics 7(3), 327-341.

Tsay, R. S. (1991), 'Two canonical forms for vector VARMA processes', Statistica Sinica 1, 247269.

Zhao-Guo, C. (1985), 'The asymptotic efficiency of a linear procedure of estimation for ARMA models', Journal of Time Series Analysis 6(1), 53-62. 